\title{
Harmful diversification: evidence from alternative investments
}

\section{Article}

\section{Accepted Version}

Creative Commons: Attribution-Noncommercial-No Derivative Works 4.0

Platanakis, E., Sakkas, A. and Sutcliffe, C. (2019) Harmful diversification: evidence from alternative investments. The British Accounting Review, 51 (1). pp. 1-23. ISSN 0890-8389 doi: https://doi.org/10.1016/j.bar.2018.08.003 Available at https://centaur.reading.ac.uk/79123/

It is advisable to refer to the publisher's version if you intend to cite from the work. See Guidance on citing.

To link to this article DOI: http://dx.doi.org/10.1016/j.bar.2018.08.003

Publisher: Elsevier

All outputs in CentAUR are protected by Intellectual Property Rights law, including copyright law. Copyright and IPR is retained by the creators or other copyright holders. Terms and conditions for use of this material are defined in the End User Agreement.

\section{www.reading.ac.uk/centaur}

\section{CentAUR}

Central Archive at the University of Reading

Reading's research outputs online 


\title{
Harmful Diversification: Evidence from Alternative Investments
}

\author{
Emmanouil Platanakis", Athanasios Sakkas ${ }^{+}$and Charles Sutcliffe*
}

22 May 2018

\# School of Management, University of Bath, Claverton Down, Bath, BA2 7AY, UK, email: E.Platanakis@bath.ac.uk Tel: +44(0) 1274235311

+ Southampton Business School, University of Southampton, Highfield, Southampton SO17 1BJ, UK, email: A.Sakkas@soton.ac.uk Tel: +44(0) 2380593551

* The ICMA Centre, Henley Business School, University of Reading, PO Box 242, Reading RG6 6BA, UK, email: c.m.s.sutcliffe@rdg.ac.uk Tel +44(0) 118378 6117, Fax +44(0) 1189314741 (corresponding author)

We wish to thank the following for their comments on earlier versions of this paper - Roger Adkins, Chengang Wang, Steven Wu and Xiaoxia Ye (University of Bradford), Nikolaos Tessaromatis (EDHEC), John Board, Chris Brooks, Mike Clements, Tony Moore, Ioannis Oikonomou, Brian Scott-Quinn, Satya Sahoo, Sotiris Tsolacos, Simone Varotto and Yeqin Zeng (University of Reading), Jeremy Eng-Tuck Cheah, Emmanouil Mentzakis, Andrew Urquhart, Jason Wang, George Xyngis and Si Zhou (University of Southampton), Yunbi An (University of Windsor), Thomas Raffinot (Paris-Dauphine University), Dimitrios Stafylas (Aston University), Robert Vermeulen (De Nederlandsche Bank N.V.), Athanasios Verousis (University of Newcastle), Dominik Wolff (Deka Investment GmbH), David Newton, Phil Tomlinson, Simon Wilde and Ania Zalewska (University of Bath), the referees and associate editor of this journal, and participants in staff seminars at the universities of Bath, Bradford, Queen's University Belfast, Reading and Southampton; and at the $26^{\text {th }}$ EFMA Conference, Athens; the $7^{\text {th }}$ FEBS International Conference, Glasgow; the $15^{\text {th }}$ INFINITI Conference, Valencia, the British Accounting and Finance Association Conference, London, the $25^{\text {th }}$ Annual Global Finance Conference, Paris and the $8^{\text {th }}$ FEBS National Conference, Athens. We also thank Marcelo Perlin (Federal University of Rio Grande do Sul) for making his MATLAB code publically available.

ORCID : Emmanouil Platanakis 0000-0003-1493-6339

Athanasios Sakkas $\quad$ 0000-0001-5348-3382

Charles Sutcliffe $\quad$ 0000-0003-0187-487X 


\title{
Harmful Diversification: Evidence from Alternative Investments
}

\begin{abstract}
Alternative assets have become as important as equities and fixed income in the portfolios of major investors, and so their diversification properties are also important. However, adding five alternative assets (real estate, commodities, hedge funds, emerging markets and private equity) to equity and bond portfolios is shown to be harmful for US investors. We use 19 portfolio models, in conjunction with dummy variable regression, to demonstrate this harm over the 1997-2015 period. This finding is robust to different estimation periods, risk aversion levels, and the use of two regimes. Harmful diversification into alternatives is not primarily due to transactions costs or non-normality, but to estimation risk. This is larger for alternative assets, particularly during the credit crisis which accounts for the harmful diversification of real estate, private equity and emerging markets. Diversification into commodities, and to a lesser extent hedge funds, remains harmful even when the credit crisis is excluded.
\end{abstract}

Key words: alternative assets; diversification; estimation errors; transactions costs; non-normality; regimes.

JEL: G11 


\section{Introduction}

The main question we address is whether investing in alternative assets is beneficial for US investors. Diversification is a fundamental principle of finance and generally accepted as offering a 'free lunch' of higher returns for a given level of risk, or lower risk for a given level of returns. Although investment in alternative assets provides greater diversification, it has been widely reported in the literature that the return characteristics of alternative assets differ from those of conventional assets ${ }^{1}$. They are subject to larger estimation errors, higher transactions costs and more non-normality of returns than other assets, and this can lead to inferior out-of-sample portfolio performance. In which case diversification into alternative assets can be harmful, rather than beneficial. Since a significant proportion of institutional portfolios is invested in alternative assets, the performance of portfolios diversified in this way is important.

In recent decades there has been a considerable increase in investment in alternative assets, and this is forecast to continue. As the growth rate in the value of investment in alternative assets has been much higher than the growth rate in the value of institutional portfolios, the relative importance of alternative assets in institutional portfolios has also increased. Pension plans are the largest group of institutional investors, and in 1995 alternative assets accounted for 5\% of the portfolios of pension schemes in Australia, UK, US, Canada, Japan, Netherlands and Switzerland (Towers Watson, 2015). By 2014 this percentage had grown to $25 \%$, and for the US it had risen to $29 \%$, making investment in alternative assets by US pension schemes larger than in fixed income. In 2014 the 64 largest pension schemes and 20 largest sovereign wealth and public pension reserve funds in 36 OECD countries allocated $30.1 \%$ of their assets of $\$ 10.3$ trillion to alternative and other assets, OECD (2016). In December 2016 Willis Towers Watson (2017) surveyed the 562 largest alternative asset managers globally and found they have \$7 trillion invested in alternative assets (hedge funds - $31 \%$, private equity - $29 \%$, real estate $-27 \%$, commodities - $1 \%$, infrastructure - $6 \%$ and illiquid credit - $6 \%$ ). These figures show that alternative assets have become as important as equities and fixed income in the portfolios of major institutional investors.

We assume that investing in equities and bonds is a given, and analyse the effects of adding five alternative assets to US equity and bond portfolios ${ }^{2}$. Definitions of alternative assets differ, and we concentrate on five important types of alternative asset for which a time series of monthly data since 1994 is available - hedge funds, real estate, private equity, commodities and emerging equity markets. We

\footnotetext{
${ }^{1}$ For example, hedge funds - Amin and Kat (2003); commodities - Gorton and Rouwenhorst (2006); private equity - Cumming et al. (2013); real estate - Myer and Webb (1994); and emerging markets - Bekaert et al. (1998).

${ }^{2}$ Traditionally investors hold a portfolio of equities and bonds to which they may add alternative assets. Whether diversification is harmful when the initial portfolio of asset classes is different from equities and bonds, or when extra securities within the same asset class are added are empirical questions we do not investigate.
} 
compare the out-of-sample performance of seven portfolios where zero, one and all five of the alternative assets are added to an equity and bond portfolio. These portfolios are formed using 19 portfolio models eight types of mean-variance analysis, eight types of ad hoc model and three models which maximize a utility function, in conjunction with three levels of risk aversion. These models are chosen to provide a broadly representative sample of portfolio formation techniques. When analysing performance, we effectively consider the average performance across all of these portfolio models as a 'horse race' between the portfolio models is outside the scope of this paper.

When estimating the portfolio input parameters we use both three and four year rolling estimation periods, and also allow for regime switching in asset returns ${ }^{3}$. We impose realistic bounds on the asset proportions, and incorporate transaction costs both when forming portfolios and when evaluating their performance. Out-of-sample performance is measured using certain equivalent returns (CERs) and Sharpe ratios. Because we have 19 portfolio techniques, in conjunction with seven combinations of assets, we are able to use dummy variable regression to estimate the differential portfolio performance of adding alternative assets, while controlling for the influence of the different portfolio models.

Our results indicate that diversification into alternative assets is harmful. We then investigate three possible explanations for this result - estimation errors, transactions costs and non-normality, and conclude that the major cause of harmful diversification is estimation errors. In the first detailed empirical analysis of the estimation errors associated with alternative assets, we demonstrate that the estimation errors in portfolio inputs are larger for most alternative assets than for equities and bonds. These errors bias portfolio weights in the expected direction, as predicted by Michaud and Michaud (2008). We also find that the total size of these biases in asset weights increases as the number of alternative assets in a portfolio is increased, which supports the theoretical and simulation results of Kan and Zhou (2007). Large estimation errors during the credit crisis are responsible for the harmful diversification of three of our five alternative assets - real estate, private equity and emerging markets. For commodities and hedge funds estimation errors during the credit crisis are not responsible for their harmful diversification. Our results indicate that investors should generally avoid investing in commodities and hedge funds, and not invest in private equity, real estate and emerging markets during crisis periods. This raises the difficult problem of forecasting crises. We ensure the robustness of our conclusions by using two different performance measures of out-of-sample returns (CERs and Sharpe ratios), a large number of portfolio models, three different levels of risk aversion and two lengths of the estimation window, and by investigating both one

\footnotetext{
${ }^{3}$ Our rolling windows are reasonably short to permit a more substantial response to changes in the data generation process.
} 
and two asset return regimes.

Our data is described in Section 3, including an explanation of how the hedge fund returns were de-smoothed. This section also reports the correlations between our seven assets, and tests our asset returns for normality. In Section 4 we present the methodology we use when estimating the out-of-sample inputs to the portfolio models, followed by a summary of the 19 portfolio models and the constant relative risk aversion (CRRA) utility function we employ. Section 5 reports our transaction cost estimates, and explains how these transaction costs are both included in the portfolio models and in the performance measures. An outline of the application of the Markov regime shifting model to our data, and the effect this has on the normality of returns appears in Section 6. Section 7 reveals how we measure performance using CERs and Sharpe ratios, followed by our results. Section 8 investigates the extent to which estimation errors (particularly during the credit crisis), transaction costs and non-normality account for the harmful effects of diversification into alternative assets. Finally, Section 9 contains our conclusions.

\section{Literature Review}

Previous studies have investigated the diversification benefits of adding a single alternative asset class to a traditional asset portfolio (e.g. commodities - Bessler and Wolff (2015), Belousova and Dorfleitner (2012); private equity - Ennis and Sebastian (2005); real estate - Chen et al., 2005, Lee and Stevenson, 2005; hedge funds - Amin and Kat, 2003). These studies conclude that diversification into each of the alternative assets that we study is beneficial. Only three previous studies have investigated the outof-sample benefits of including two or more of our five alternative assets when short sales are prohibited. Two of these studies (Jackwerth and Slavutskaya (2016) and Sa-Aadu et al, 2010) find that diversification into alternative assets improves performance, but have important differences from the current study. Neither paper incorporates transaction costs. Jackwerth and Slavutskaya consider three of our five assets, but do not examine optimized portfolios, while Sa-Aadu et al analyse only two of our five assets and use a data period that excludes most of the credit crisis. As well as banning short sales and examining out-ofsample performance, the third study (Jacobs et al, 2014) allows for transaction costs, but covers only two of our five assets. They find that diversification improves performance for three optimization techniques, but for another three optimization techniques diversification is harmful.

\section{Data and Descriptive Statistics}

3a. Data. We analyse monthly returns from January 1994 to December 2015 for five alternative asset classes - commodities (S\&P GSCI total return index), real estate (FTSE EPRA/NAREIT global real estate total return index), private equity (LPX 50 listed private equity total return index), emerging markets (MSCI emerging markets total return index) and hedge funds (HFRI fund of funds composite total return index). 
The data for these five alternative assets are based on international portfolios of the underlying assets, and their returns are expressed in US dollars. We also analyse monthly returns for the same period on US equities (S\&P 500 composite total return index) and US bonds (Barclays US aggregate total return index) in US dollars ${ }^{4}$. This bond index covers Treasury bonds, government-related securities, corporate bonds and securitizations. All the assets we study are exchange traded, except for hedge funds where there are no exchange traded indices.

3b. De-smoothing Hedge Fund Returns. Hedge fund returns are based on non-market valuations of the underlying assets, which brings with it the problems of an illiquid market and managed returns, leading to smoothed and biased returns. Return smoothing creates positive serial correlation in returns, and reduces the variance and correlations with other assets (e.g. Agarawal et al, 2011; Cassar and Gerakos, 2011; Bollen and Pool, 2008, 2009). While many previous researchers have ignored this problem, some have addressed the smoothing of hedge index returns by transforming (de-smoothing) them to approximate the unsmoothed returns. Five methods for de-smoothing hedge fund returns have been proposed, and we use the Geltner $(1991,1993)$ method which is simple and widely used ${ }^{5}$. The unsmoothed return series $\left(r_{t}^{\circ}\right)$ is computed as:-

$$
r_{t}^{\circ}=\left(r_{t}-\rho r_{t-1}\right) /(1-\rho)
$$

where $r_{t}$ is the original smoothed series, and $\rho$ is its first order autocorrelation.

As well as return smoothing, the way hedge fund indices are constructed introduces various biases (e.g. survivorship bias, self-selection bias, and backfill bias) which may increase or decrease mean returns ${ }^{6}$. However Edelman et al (2013), Fung and Hsieh (2000, 2002, 2004), Ackermann et al (1999) and Pictet Alternative Advisors (2015) argue that these biases in hedge fund returns tend to be offsetting, and that the use of an index of funds of funds mitigates them even further. Because we are using a composite fund of funds index we do not adjust hedge fund returns for these biases.

\footnotetext{
${ }^{4}$ The private equity data came from Bloomberg, and the remaining data came from Datastream.

${ }^{5}$ The method of Geltner $(1991,1993)$ has been widely used for real estate returns, and applied to hedge
} funds by Bekkers et al (2009); Brooks and Kat (2002); and Hoevenaars et al (2008). Getmansky et al (2004) developed a method which they used to adjust hedge fund returns, and their method has also been used on hedge funds by Boigner, and Gadzinski (2015). Okunev and White (2004) adjusted hedge fund returns using their own method, which has also been used by Cavenaile et al (2011) and Bird et al (2013) for de-smoothing hedge find returns. Pedersen et al (2014) have used their own method for de-smoothing hedge fund returns, while the desmoothing method of Bond et al (2007) has not been applied to hedge fund returns.

${ }^{6}$ Agarawal et al (2013), Agarawal et al (2015), Aiken et al (2012), Fung and Hsieh (2000, 2002), Malkiel and Saha (2005) and Posthuma and Van der Sluis (2003). 
3c. Normality Tests. Mean-variance portfolio analysis assumes either that returns are normally distributed, or that investors have a quadratic utility function. Since quadratic utility is subject to serious objections, the use of mean-variance analysis rests on the normality of asset returns. If this assumption is not met higher moments of the return distribution, such as skewness and kurtosis, may be important to investors. Many previous studies have applied the Jarque-Bera normality test to asset returns and confirmed that alternative asset returns have non-normal distributions. Table 1 shows the first four moments of returns for the seven assets over our full sample period, as well as three normality tests. The numbers in Table 1 were computed using monthly returns, but following Cumming et al (2014), their annualized values are shown in the table. There is significant negative skewness for all the asset classes except bonds, and significant positive kurtosis for every asset class. The normality tests confirm that all asset returns, except bonds, are non-normal at the $1 \%$ level on all three tests, and bond returns are non-normal at the $5 \%$ level using the Jarque-Bera and Shapiro-Wilk tests. Therefore our data contains significant and widespread nonnormality due to both skewness and kurtosis, making the use of mean-variance analysis questionable. Applying mean-variance dominance to the first two moments of the seven assets in Table 1, equities dominate both commodities and emerging markets, bonds dominate hedge funds which then dominate commodities, and real estate dominates private equity, commodities and emerging markets. So equities, bonds and real estate are the only undominated assets.

\section{INSERT TABLE 1 NEAR HERE}

3d. Correlations. We report the correlations for monthly returns in Table 2. The highest correlation is 0.75 , while 12 of the 30 correlations for alternative assets are less than 0.50 , and five correlations (all with bonds) are not significantly different from zero. This suggests considerable diversification benefits are available from adding alternative assets to a portfolio of equities and bonds.

\section{INSERT TABLE 2 NEAR HERE}

\section{Methodology}

To allow for the non-stationarity of returns, our analysis is based on the 'rolling windows' approach, with an estimation window of 36 (or 48) months used to compute the optimal asset allocations for each portfolio model over the next out-of-sample month ${ }^{7}$. The estimation window is then advanced by one month, and the process repeated 228 (216) times. Since the length of the rolling estimation window is indeterminate, for robustness we use both 36 and 48 months. Similarly, we employ both one and two

\footnotetext{
${ }^{7}$ This assumes portfolios are revised each month, as have previous authors, e.g. DeMiguel, et al (2009), Kirby and Ostdiek (2012) and Tu (2010).
} 
regime models to forecast the portfolio inputs. This leads to four cases - one regime and 36 months, one regime and 48 months, two regimes and 36 months, and two regimes and 48 months.

4.1 The Portfolio Models. We use a wide variety of portfolio models to increase the generality of our results. Our 19 portfolio models can be divided into three main groups - mean-variance, ad hoc and utility functions. We list these in Table 3, with further details of each model in the Appendix. Solving portfolio problems with a small number of assets in the presence of estimation errors can result in unrealistic asset weights, e.g. $100 \%$ of the assets in a single alternative asset. Therefore upper bounds have been placed on the asset weights by many previous studies of alternative assets to rule out unrealistic solutions. Pension schemes have, on average, $25 \%$ of their assets in alternatives (Towers Watson, 2015), and this suggests that optimal solutions with more than half the assets in alternative assets, are unrealistic. So we impose an upper bound of $50 \%$ on the sum of the alternative asset allocations.

\section{INSERT TABLE 3 NEAR HERE}

4.2 Utility Function. Since our individual asset returns are non-normal, portfolio returns are also likely to be non-normal, and mean-variance analysis may be unsatisfactory because it considers only the first two moments of the return distribution. The usual solution is to maximise a utility function, and the two most widely used are the CRRA (or power) utility function, and the constant absolute risk aversion (CARA or exponential) utility function. Both of these utility functions imply investors have a positive preference for skewness (the third moment), and a negative preference for kurtosis (the fourth moment), as well as a positive preference for the mean (the first moment), and a negative preference for the variance (the second moment), Scott and Horvath (1980) ${ }^{8}$. Kallberg and Ziemba (1983) found that six utility functions, including CRRA and CARA, lead to similar optimal portfolios for horizon periods of up to one year. The CRRA utility function has the advantage that, since relative risk aversion is constant, the asset allocation is independent of investor wealth, allowing performance measurement to use either the level of wealth at the end of each period, or the return each period. So, in common with many previous researchers, we assume that investors have a time-separable CRRA utility function and unit initial wealth:-

$$
U_{t}=\left(1+r_{t}\right)^{1-\lambda} /(1-\lambda)
$$

where $r_{t}$ is the portfolio return in period $t$, and $\lambda$ is the investor's risk aversion parameter. Some researchers have maximized a utility function by using either numerical quadrature or Monte Carlo

\footnotetext{
${ }^{8}$ Table 1 documented the presence of negative skewness in asset returns which appeals to investors who exhibit imprudence, and excess positive kurtosis which is attractive to investors who display intemperance. So consideration of the third and fourth moments will tend to make these assets less attractive to investors with a CRRA utility function. (Eeckoudt and Schlesinger, 2006).
} 
simulation. These approaches are only practical when there are just two or three assets, and we have seven assets, making these methods impractical. Therefore, in common with many previous studies, we use a Taylor series expansion?.

\section{Transaction Costs}

Transaction costs are an important aspect of the asset allocation decision, particularly for alternative assets. This is the first study of two or more alternative assets to allow for transaction costs when computing the optimal portfolios, as well as when measuring performance. The value of the trades and the associated transaction costs involved in rebalancing a portfolio are affected by the initial asset allocation because a substantial alteration to the asset allocation generates higher transaction costs than one which is similar to the current allocation. This makes large rebalancings less attractive. When transaction costs are included, the previous asset allocation affects net returns for the next period, making the optimal asset allocation decision path dependent. Even when the initial asset allocation is entirely in cash, if transaction costs differ between assets they will still affect the optimal solution.

We introduce transaction costs into our optimizing models by including the total transaction costs $\left(T C_{j}\right)$ in the various objective functions:-

$$
T C_{j}=\sum_{i=1}^{n}\left(\left|x_{i j}-x_{i j-1}^{*}\right|\right) T_{i}
$$

where $T_{i}$ is the proportionate transaction cost for trading the $i^{\text {th }}$ asset, and $x_{i j-1}^{*}$ is the proportion of the value of the portfolio at the end of the previous period (i.e. $j-1$ ) in asset $i$, allowing for price changes during that period (Olivares-Nadal and DeMiguel, 2015). We assume transaction costs are a linear function of trade value, and are the same for buys and sells ${ }^{10}$. In our mean-variance and utility models $T C_{j}$ is subtracted from the expected portfolio return ${ }^{11}$. The effect of transaction costs on the asset allocation decision depends on the period over which the transaction costs are expected to be spread,

\footnotetext{
${ }^{9}$ The Taylor series expansion is an approximation, and we use the first four terms to approximate the entire series. Garlappi and Skoulakis (2011) have found that, for the CRRA utility function and four asset portfolios, a Taylor series expansion of order four is reasonably accurate when portfolio returns are normal. When portfolio returns are non-normal its accuracy decreases as risk aversion increases, and for risk aversion of 10 it leads to a proportionate error of $3 \%$ in the CER. A Taylor series expansion of a CRRA utility function only converges for values of wealth between zero and twice the expected wealth, Loistl (1976). For our data the CRRA convergence limits are met.

${ }^{10}$ We only consider the variable transaction costs of trading assets, and ignore the fixed costs of establishing and maintaining the systems to invest in each asset class. Inclusion of these costs in the models would reinforce the conclusion that investing in alternative assets is not beneficial.

${ }^{11}$ No transaction costs are included when forming portfolios using the ad hoc models (except for combination: $1 / N$ \& minimum variance and combination: $1 / N$, minimum variance \& Markowitz), although they are included when measuring performance.
} 
i.e. the expected holding period (Woodside-Oriakhi, et al, 2013). A survey of the equity trades of almost 1,000 active institutional managers for 2006-2009 by the IRRC Institute (2010) found the average expected holding period is 1.75 years ( 21 months), so we divide our transaction costs by 21 to get their expected effect on monthly returns ${ }^{12}$.

The transaction costs for an institutional investor trading a particular asset vary over time as well as between investors making it hard to specify a single figure for an asset, and previous authors have used a very wide variety of transaction costs. For example, French (2008) estimated the transaction cost of trading US equities at 11 basis points (bps) in 2006, while Kourtis (2015) used 100 bps. We estimate the proportionate transaction costs of trading equities in developed markets at $50 \mathrm{bps}$, as have DeMiguel et al (2009), Kirby and Ostdiek (2012) and Daskalaki and Skiadopoulos (2011). Since the returns for REITs and listed private equity are based on assets traded on developed equity markets we also use 50 bps for real estate, as have Clare et al (2016), and 50 bps for private equity. Emerging equity markets have higher transaction costs than developed equity markets, and we estimate these at 55 bps, as have Clare et al (2016). Commodity investment is usually achieved via commodity futures which have a life of a few months before they are delivered, and to maintain a position for a year the futures position has to be rolled over several times. Clare et al (2016) use a transaction cost for commodities of $8 \mathrm{bps}$, and as we allow for rolling over the position four times per year, this gives an annual cost of about $32 \mathrm{bps}$. We adopt the estimate of 35 bps of Daskalaki and Skiadopoulos (2011) for commodities. Edwards et al (2007) have estimated the transaction cost of a $\$ 200,000$ corporate bond trade at $17 \mathrm{bps}$, which is also the cost used by Clare et al (2016) for bond trades, and we also use this number.

The only unlisted asset class we consider is hedge funds. Investment in a fund of hedge funds is a cash inflow to the fund, which then invests in a range of hedge funds, without using organized financial markets. The management and performance fees for funds of hedge funds have been estimated at $1.78 \%$ per year by French (2008), and are deducted from their reported returns so that these costs are already allowed for in returns. Therefore the additional transaction costs paid by institutional investors when they invest in a fund of hedge funds are low, and following Hocht et al (2008), we use a transaction cost of 50 bps.

Since our portfolio models use monthly returns, before including the above transaction costs in our portfolio models we divide them by the expected holding period of 21 months, giving costs of $2.4 \mathrm{bps}$ for equities, real estate, private equity, real estate and hedge funds, 2.6 bps for emerging markets, 1.7 bps for commodities and 0.8 bps for bonds. However, when measuring performance we include the full transaction cost of the trades involved in rebalancing the portfolio.

\footnotetext{
12 The actual holding period found by the IRRC Institute is only 1.40 years.
} 


\section{Markov Regime Switching}

There is considerable evidence that asset returns, risks and correlations shift with the economic regime (e.g. Guidolin, 2011). In a study of US equities, Tu (2010) concludes that allowance for regime switching generally improves out-of-sample portfolio returns when long estimation periods are used. Our data covers three bull markets for US equities (October 1994 to January 2000, July 2002 to July 2007, and January 2009 onwards) separated by two major bear markets (January 2000 to July 2002 and July 2007 to January 2009). Therefore we allow the distributions of assets returns and the relationships between them to shift according to the prevailing economic regime. Only Sa-Aadu et al (2010) and Hocht et al (2008) have applied a Markov regime shifting model to portfolios with two or more alternative assets. They used the two-state Markov chain analysis of Hamilton $(1989,1990)$ which assumes that asset returns are a mixture of normals, and uses maximum likelihood estimation. For portfolios with two alternative assets, the two-regime model of Sa-Aadu et al (2010) generated superior out-of-sample performance in terms of both Sharpe ratios and CERs when using two regimes, rather than one.

Assuming the non-normality evidenced in Table 1 is due to asset returns being a mixture of two normals (one for each regime), and following Ang and Bekaert (2004) and Ang and Timmermann (2012) amongst others, we fit a two state multi-variate regime-switching model using MS_Regress (Perlin, 2015) to asset returns for each rolling window estimation period ( 36 or 48 months). For each month, when the smoothed conditional probability over the estimation period is higher (lower) than $50 \%$, that month is classified as being in state 1 (state 2), Kim (1994). Based on the realization of the regime in the last month of each estimation period (Ang and Bekaert, 2004), we compute the first four moments and the covariance matrix, as defined by Timmermann (2000) and Ang and Timmermann (2012), for the next outof-sample month. We then use these estimates as inputs to our 19 portfolio models ${ }^{13}$. The results in Table 4 broadly support the mixture of two normals assumption. None of the skewness statistics, and only three of the kurtosis statistics (one in the low volatility regime, and two in the high volatility regime) are statistically significant at the $5 \%$ level. This contrasts with Table 1 where all but bonds exhibit skewness, and all the assets demonstrate kurtosis. So with a single regime all seven assets are highly non-normal, but with two regimes most assets become normal, and where they remain non-normal, the nonnormality is much reduced ${ }^{14}$.

\section{INSERT TABLE 4 NEAR HERE}

To investigate the mixture of two normals assumption further, Table 5 has normality tests for the

\footnotetext{
${ }^{13}$ The $1 / \mathrm{N}$ model is regime independent.

${ }^{14}$ The correlation matrices for the high and low volatility regimes are reasonably similar, with an average correlation of 0.352 for the low volatility regime, and 0.406 for the high volatility regime.
} 
monthly returns in each of the two regimes we have identified. In every case, with the exception of bonds in the low volatility regime, all the normality test statistics for the two regimes are lower than in Table 1 , and in some cases a lot lower. With two regimes equity, emerging markets and hedge fund returns are normal in both regimes on all three tests. In the high volatility regime bonds and commodities are normal according to all the tests, and private equity is normal at the $5 \%$ level in the low volatility regime on all three tests. So the use of two regimes has greatly increased the normality of returns of our seven assets, and most assets are now normally distributed.

\section{INSERT TABLE 5 NEAR HERE}

We now use the regime classification measure (RCM) of Ang and Bekaert (2002a) to investigate the success of our regime shifting analysis in distinguishing between the two regimes. The RCM statistic lies between zero and 100, where a score of 100 indicates the model cannot distinguish between the regimes. The RCM score for our two regimes is 12.855 , and since this number is reasonably close to zero, it supports the view that we are distinguishing between two regimes.

Table 6 tests for significant differences between the means and variances of monthly returns for the two regimes across the sample period. Ang and Bekaert (2002c, 2004) find that for equities the high volatility regime has lower mean returns, while for bonds Ang and Bekaert (2002a, 2002b) find that the high volatility regime has higher returns. Table 5 shows that these conclusions also apply to our data, with the low volatility regime having significantly higher mean returns for US equities, private equity and hedge funds, while bonds have significantly lower mean returns in the low volatility regime. We use the Levene (1960) test for unequal variances because it is robust to non-normality, and this shows that for every asset, except bonds, the variance of monthly returns in the high volatility regime is significantly higher than in the low volatility regime.

\section{INSERT TABLE 6 NEAR HERE}

\section{Results}

For each of our seven asset portfolios and 19 portfolio models we generate a time series of 228 portfolio returns for three year rolling window estimation periods, and 216 returns for four year estimation periods. This produces $(19 \times 7)=133$ out-of-sample returns for each of our four cases. We solve each case for three levels of risk aversion $(\lambda=2,5$ and 10), allowing an investigation of whether the benefits of diversification differ with risk aversion. This requires the solution of 313,908 portfolio problems.

7.1. Performance Measurement. Smetters and Zhang (2014) show that, if portfolio returns are normally distributed, Sharpe ratios correctly rank portfolios; but if portfolio returns are non-normal, investor 
preferences may be required to rank portfolios. While the returns on our seven individual assets are clearly non-normal when we use one regime, it is possible that the out-of-sample returns on the portfolios formed using our 19 different models are normal ${ }^{15}$. In which case the use of Sharpe ratios is appropriate. We tested the normality of the 228 (216) out-of-sample returns for each of our 133 asset allocations for three (four) year estimation periods when $\lambda=5$, and we report these results in Table 7 . This shows that the vast majority of our 133 portfolios across the four cases have non-normal returns. Therefore the use of Sharpe ratios is problematic for our data, and we use CERs as our primary measure of portfolio performance. CERs are the riskless rate of return that gives the same utility as the risky returns on the portfolio. The CER for a CRRA utility function is computed as:-

$$
\mathrm{CER}_{\mathrm{t}}=\left\{(1-\lambda) E\left[U_{\mathrm{t}}\right]\right\}^{1 /(1-\lambda)}-1
$$

where $E[U]$ is the mean utility across our out-of-sample periods (Diris et al, 2015).

\section{INSERT TABLE 7 NEAR HERE}

We regress these CER values on two sets of 0-1 dummies, where $D A_{i}$ denotes the $i^{\text {th }}$ asset set, and $D T_{j}$ denotes the use of the $j^{\text {th }}$ portfolio model. The regression model is:-

$$
C E R_{i j}=\alpha+\sum_{i=2}^{7} \beta_{i} D A_{i}+\sum_{j=2}^{19} \delta_{j} D T_{j}+\varepsilon_{i j}
$$

We include a constant term and drop the dummy variables $D A_{1}$, which indicates portfolios of equity and bonds, and $D T_{1}$ which indicates the Markowitz model ${ }^{16}$. Therefore the constant term in equation (5) is the predicted CER for an equity and bond portfolio formed using the Markowitz model, the $\beta_{i}$ give the estimated difference between the CER for the $i^{\text {th }}$ portfolio of assets and that for equities and bonds, and the $\delta_{j}$ give the estimated difference in the CER for the $j^{\text {th }}$ model and that for Markowitz ${ }^{17}$. We apply the Breusch-Pagan test to the residuals of our regressions, and where heteroskedasticity is detected at the $5 \%$ level we report robust standard errors (Breusch and Pagan, 1979). As our data is cross-section and has only 0-1 dummies as explanatory variables, there is no need to test for multicollinearity or autocorrelation.

7.2 CER Results. We report the estimated coefficients for the $D A_{i}$ for three different levels of risk aversion

\footnotetext{
${ }^{15}$ The central limit theorem means portfolio arithmetic returns tend to be more normal than individual asset returns.

${ }^{16}$ We have benchmarked the results from our 19 portfolio models to those of the Markowitz model because it is very widely used in the literature.

${ }^{17}$ We have not included any interactions between the $D A_{i}$ and $D T_{j}$ in equation (5) because there are $(6 \times 18)$ $=108$ such interactions, and we only have one observation for each interaction.
} 
and our four combinations of regimes and estimation periods in Table $8^{18}$. The coefficients of the six portfolios show the marginal effect of adding each alternative asset individually, and all five alternative assets together, to a portfolio of equities and bonds formed using the Markowitz model. The $18 D T$ dummies are included in the regressions to control for the effects of using different portfolio models, but are not reported in Table 8 as a 'horse race' between portfolio models is not the purpose of this research ${ }^{19}$. The results in Table 8 give the average performance across all 19 portfolio models. The data underlying Table 8 is available from the authors and shows there is not a sub-set of portfolio models where diversification is beneficial.

\section{INSERT TABLE 8 NEAR HERE}

Across our four cases, portfolios containing all seven assets have significantly lower CERs for nine regressions, while two of the remaining cases are also lower, but not significant. This indicates that equity and bond portfolios are superior to those which also contain the five alternative assets. This result is generally supported by the results for adding individual alternative assets to the equity and bond portfolio. Out of sixty coefficients for the five individual alternative assets, four cases and three $\lambda$ values, only nine are significantly positive, while 28 are significantly negative. This result indicates that diversification is harmful, rather than beneficial, with the harm getting stronger as risk aversion increases. In Section 8 we investigate the reasons for this surprising result.

The predicted CERs from equity and bond portfolios formed using the Markowitz model (i.e. the constant terms in equation (5)) decrease as risk aversion increases. This is because, although increasing the level of risk aversion when forming portfolios leads to an increase in the constant terms, this is more than outweighed by the decrease in the constant terms when higher risk aversion is used to evaluate these portfolios. So the net effect on the constant terms is a decline as risk aversion increases. The constant terms also decrease when two regimes and a four year estimation period are used, suggesting that the use of a single regime and three year estimation period is preferable.

7.3 Sharpe Ratio Results. As a robustness check, and to investigate the extent to which non-normal returns lead to different performance measurements from those provided by CERs, we also compute the Sharpe ratios for each of our 133 time series of out-of-sample returns. As for CERs, we regress the Sharpe ratios on the two sets of dummy variables in equation (5), and we report the results for our three levels of risk aversion and four cases in Table 9. Across our four cases, portfolios containing all seven assets

\footnotetext{
${ }^{18}$ The CER values for each portfolio technique and asset portfolio are available on request from the authors.

${ }^{19}$ Oikonomou et al (forthcoming) show that the portfolio model matters.
} 
have a significantly lower Sharpe ratio at the $1 \%$ level for all twelve regressions ${ }^{20}$. So, as for CERs, portfolios containing all seven assets are inferior to portfolios of just equities and bonds. Out of sixty coefficients for the five individual alternative assets, four cases and three $\lambda$ values, only five are significantly positive, while 37 are significantly negative. The Sharpe ratios indicate even more strongly than the CER results that diversification is harmful.

\section{INSERT TABLE 9 NEAR HERE}

The length of the estimation period and the number of regimes have a similar effect on the Sharpe ratio and CER constants. The constant terms in the Sharpe ratio regressions decrease when two regimes and four year estimation periods are used, again suggesting that the use of a single regime and a three year estimation period is preferable. Unlike the CER regressions, the constant terms in the Sharpe ratio regressions increase with risk aversion. This is because the level of risk aversion affects the formation of portfolios, but not their evaluation using Sharpe ratios. As for CERs, higher risk aversion leads to higher Sharpe ratios, but this is not offset by higher risk aversion when evaluating these ratios.

These results for both CERs and Sharpe ratios indicate that adding alternative assets to a portfolio of equities and bonds tends to lead to a deterioration in out-of-sample performance. This is particularly apparent when all five alternative assets are included to the portfolio. Therefore, in contradiction to Markowitz (1952), diversification is harmful.

\section{Explanations for Harmful Diversification}

Markowitz (1952) has shown that diversification improves the performance of mean-variance portfolios, assuming no estimation errors or transaction costs, the correlations between assets are less than unity, and returns are normally distributed or utility is quadratic ${ }^{21}$. There is also a substantial literature which has demonstrated empirically that diversification reduces portfolio risk, e.g. Evans and Archer (1968). However these empirical demonstrations of the benefits of diversification use a $1 / N$ asset allocation strategy. When forming portfolios $1 / N$ takes no account of estimation errors, transaction costs, the correlations between assets, the distribution of returns or the investor's utility function. Since our correlations are well below unity, this suggests harmful diversification is caused by estimation errors, transaction costs, non-normality, or some mixture of these three explanations. Therefore we now investigate the causes of harmful diversification by exploring the effects of transaction costs, nonnormality and estimation errors.

\footnotetext{
${ }^{20}$ The coefficients for the dummy variables of the other 18 portfolio models are not reported in Table 9.

${ }^{21}$ If one asset has a very high return and low risk, mean-variance analysis can lead to investment in a single asset, but in competitive markets this would be an exceptional situation. Egozcue, et al (2011) have shown that, if an investor has a convex utility function over the relevant range, they will invest in a single asset.
} 
8.1 Transaction Costs. If all assets have identical variable transaction costs and there are no fixed costs for investing in an additional asset, the asset allocation and relative performance of portfolios containing different numbers of assets are unaffected when allowance is made for transaction costs. However, differential variable and fixed transaction costs exist, and so transaction costs can affect portfolio composition and relative portfolio performance. Jennings and Payne (2016) argue that alternative assets have such high transaction costs that they make diversification into these assets unattractive. In Section 5 our estimates show that emerging markets have the highest transaction costs, equities, commodities, hedge funds, real estate and private equity all have the same transaction costs, and bonds have the lowest transaction costs. Therefore any transaction cost effect on performance is not due to alternative assets having markedly higher transaction costs than equities and bonds, but to the increased turnover generated by rebalancing the portfolio across more assets, and to the choice of different asset weights due to the incorporation of transaction costs in the objective function.

We report the average reductions in expected returns due to transaction costs across our 19 portfolio models in Table 10. The transaction costs for two regimes are substantially higher than for one regime, as the use of two regimes leads to much more trading. The average transaction costs for seven asset portfolios are the highest, and those for two asset portfolios the lowest. This differential effect on average expected returns is about $0.34 \%$, and suggests that the presence of transaction costs might be partly responsible for harmful diversification. But this analysis ignores the possibility that the inclusion of transaction costs leads to the choice of different asset weights, which then affect the portfolio's first four moments. Therefore we need to compare the performance of optimal portfolios with and without transaction costs.

\section{INSERT TABLE 10 NEAR HERE}

To investigate the effects of transaction costs on portfolio performance we re-estimated our 19 models with zero transaction costs when both forming and evaluating portfolios, and the results for $\lambda=$ 5 for our four cases are available from the authors ${ }^{22}$. Comparing these results with those in Tables 8 and 9, the constant terms are increased for both the CERs and Sharpe ratios, partly due to the absence of transaction costs; while the smaller negative slope coefficients indicate that the harmful diversification effect is reduced, but still clearly present. So the presence of transaction costs does not explain our finding that diversification is harmful; they just cause a modest increase in the magnitude of the harm.

8.2 Non-Normal Returns. Tu and Zhou (2004) show that non-normal asset returns lead to substantial changes in portfolio weights, but have only a small effect on quadratic utility. Jondeau and Rockinger

\footnotetext{
${ }^{22}$ This involved solving 114,996 portfolio problems.
} 
(2006) have found that the mean-variance portfolio is a good approximation to that which maximises expected CRRA and CARA utility for moderate departures from normality. But for large departures, using the first four moments may be superior to mean-variance analysis in terms of the expected return. Other researchers have also found that the performance of mean-variance analysis suffers when returns are non-normal, see Cvitanic et al (2008), Cremers et al (2004), Cumming et al (2014) and Xiong and Idzorek (2011). Their results suggest that, when the departure from normality is substantial and volatility is high, there can be important differences between the performance of mean-variance portfolios and those which also rely on higher moments.

Tables 1, 4, 5 and 7 show that returns on individual assets and portfolios are highly non-normal, while Tables 4 and 5 indicate that the use of two regimes leads to a big reduction in this non-normality. This suggests that portfolio models which allow for non-normality will produce higher CERs than models which do not. To test this we compare the performance of the three models which maximise CRRA utility (which includes the first four moments), with that for the corresponding three Markowitz models (which only include the first two moments). For each of our four cases we rerun the regression in equation (5), except that we vary the benchmark portfolio. We used the three Markowitz models (1, 2 \& 3 in Table 3 ) in turn as the benchmark portfolio model, in conjunction with equities and bonds. We report the estimated coefficients for the CRRA model $(17,18$ \& 19 in Table 3) corresponding to each of the three benchmark Markowitz portfolio models in Table 11 together with their significance levels in brackets. The coefficients in this table are very small, and a very long way from being statistically significant, indicating that allowing for the non-normality of asset returns has no discernable effect on Markowitz portfolio performance.

\section{INSERT TABLE 11 NEAR HERE}

We repeat the analysis in Table 11 but for Sharpe ratios, and the results are available from the authors. The coefficients are even smaller than for CERs, again indicating no effect for non-normality.

When a quadratic utility function is used to measure performance the mean-variance models do not require normality. So we re-evaluate the performance of our 19 models using a quadratic, rather than a CRRA utility function, in the presence of transaction costs and estimation errors. The patterns of significant results for CERs based on a quadratic utility function are very similar to those in Table 8 for a CRRA utility function, indicating that the normality assumption does not affect our conclusions (these results are available from the authors). The results for a quadratic utility function are also consistent with the finding in Table 9 that harmful diversification remains present when the Sharpe ratio, which assumes normality, is used to measure performance.

8.3 Estimation Errors. Portfolio optimization inputs usually contain estimation errors. Previous 
researchers have found that errors in expected returns have a bigger effect on portfolio performance than do errors in the variances and covariances ${ }^{23}{ }^{24}$. Therefore we concentrate on the effects of errors in estimating expected returns. The mean-variance portfolio model tends to over (under) weight assets whose expected returns are over (under) estimated, or whose variance and covariances are under (over) estimated, (Michaud and Michaud, 2008; Kolm, et al, 2014). This has two implications. First, there is a positive correlation between estimation errors and portfolio weights. Second, with seven assets in the portfolio the effects of estimation errors are bigger than when only two or three assets available ${ }^{25}$.

Errors in estimating out-of-sample asset returns may be higher for alternative assets than for equities and bonds, making their inclusion less attractive. In Table 12 we measure estimation errors from the historical means in three ways - mean absolute error (MAE), mean squared error (MSE) and their standard deviation (SD) ${ }^{26}$. This shows that bonds clearly have the lowest estimation errors for out-ofsample returns. Hedge funds are the next most predictable asset, followed by equities. The other four alternative assets all have higher estimation errors than equities and bonds, suggesting that the benefits of diversification into alternatives may be reduced by their higher estimation errors.

\section{INSERT TABLE 12 NEAR HERE}

To explore the first implication of Michaud and Michaud (2008) we compute the correlation between estimation errors (i.e. the expected asset return less the actual out-of-sample asset return) for our seven assets and the asset weights $\left(w_{i j k}\right)$ for each of the 13 portfolio models which are affected by estimated mean returns ${ }^{27}$, for $i=1$ to 7 assets, $k=1$ to 7 portfolios using $j=1$ to 228 (216) observations. This produces 24 correlations for each portfolio model, value of $\lambda$, estimation period and number of regimes. In Table 13 we report the percentage of these $24 \times 14=336$ correlations that are significantly

\footnotetext{
${ }^{23}$ Chopra and Ziemba (1993), Kallberg and Ziemba (1984), Kan and Zhou (2007), Bengtsson (2004), and Cho (2011).

${ }^{24}$ We are concerned with the effects of estimation errors on portfolio performance, not asset weights.

${ }^{25}$ Ledoit and Wolf (2004) show that if asset returns are independently and identically distributed, the higher is the ratio $N / T$, where $N$ is the number of assets and $T$ is the number of observations, the greater are the errors in covariance matrices estimated using historic returns. Since $\delta(N / T) / \delta N>0$, an increase in the number of assets, with an unchanged number of observations, increases the errors in estimating the covariance matrix of the resulting portfolio. As the ratio $N / T$ is a linear function of $N$, portfolio problems with seven assets and $36(48)$ observations have an $N / T$ ratio that is 3.5 (3.5) times larger than for portfolios with only two assets.

${ }^{26}$ Welch and Goyal (2008) and Bossaerts and Hillion (1999) have shown the historic mean is the best way to estimate the expected equity returns, and Thornton and Valente (2012) have reached a similar conclusion for expected bond returns.

${ }^{27}$ All the ad hoc techniques in Table 3 were omitted, except for 'reward to risk timing'. When all 19 techniques are included the results are broadly similar, although less pronounced, to those for the 14 techniques as they now include the five techniques which are unaffected by estimation errors in mean returns.
} 
different from zero at the $10 \%$ level $^{28}$ for each combination of $\lambda$, estimation period and number of regimes. These results support a positive link between estimation errors and asset weights for all four of our cases, indicating that errors in estimating returns affect portfolio allocations, with an over (under) estimate of an asset's returns leading to a increase (decrease) in its portfolio weight.

\section{INSERT TABLE 13 NEAR HERE}

The second prediction of Michaud and Michaud (2008) is that portfolio performance is degraded by the inclusion of additional assets. Kan and Zhou (2007) have shown that, if asset returns are multivariate normal and independently and identically distributed, Markowitz portfolios formed with short sales permitted and using historic returns and covariances have a worse out-of-sample performance than portfolios formed using the population values. If the covariance matrix is known and estimation errors are confined to expected returns, the performance loss from using historic returns simplifies to $N /(2 \lambda T)$, where $N$ is the number of assets in the portfolio, $T$ is the number of observations, and $\lambda$ is the investor's risk aversion coefficient. This shows that increasing the number of assets in a portfolio increases the loss of performance, as does a decrease in risk aversion (Kan and Zhou, 2007), which is consistent with our empirical finding that portfolios with more assets have a worse performance ${ }^{29}$. Levy and Simaan (2016) have also argued that, due to estimation risk, adding additional assets to the choice set can make investors worse off.

To quantify the effects of estimation errors on portfolio returns we compute the MSE (where errors are the expected return minus actual return) for every out-of-sample period for each of our seven portfolios. These errors incorporate the efforts of various portfolio models to counteract the effects of estimation errors, as well as the error amplification of mean-variance models, e.g. Bayes diffuse prior, Bayes-Stein, Black-Litterman and Michaud. Table 14 has the MSE averaged across the 14 portfolio models subject to estimation errors in the means ${ }^{30}$. The MSE values drop as $\lambda$ increases, indicating that the effects of estimation errors are a smaller problem for risk averse investors ${ }^{31}$. The seven asset portfolios have the highest MSEs throughout Table 14, and the equity and bond and equity, bond and hedge fund portfolios

${ }^{28}$ The significance of these correlations from zero relies on a $t$-test $\left(t=\rho \sqrt{ }\left[(n-2)\left(1-\rho^{2}\right)\right]\right)$ which holds approximately if the value of the underlying variables are non-normal, Stuart et al (1999).

${ }^{29}$ In addition, even when there are no estimation errors, if asset returns are highly non-normal the introduction of additional assets in a portfolio can increase portfolio risk. Los (2003) shows that, if the stability exponent (which determines the kurtosis of the distribution of returns) is less than unity, $1 / N$ diversification can increase portfolio risk.

${ }^{30}$ The results for all 19 techniques are broadly similar.

${ }^{31}$ The MAEs and standard deviations give broadly similar rankings - the equities and bonds have the lowest values, and the portfolios of all seven assets have the highest values. 
have the lowest MSEs. These results are consistent with the theoretical predictions of Kan and Zhou (2007) that portfolios with more assets and those formed by less risk averse investors have higher estimation errors, leading to worse portfolio performance.

\section{INSERT TABLE 14 NEAR HERE}

8.3.1 Estimation Errors and Diversification. The results in Tables 12 and 13 show that estimation errors are larger for alternative assets, and that these estimation errors have a positive correlation with portfolio asset weights. Table 14 demonstrated that portfolios with alternative assets have larger differences between expected and actual portfolio returns than equity-bond portfolios. These results are consistent with the conclusion that alternative assets have larger estimation errors, which adversely affect portfolio asset weights, leading to worse out-of-sample performance for portfolios with alternative assets. To investigate further we re-solve our 19 models with the estimation errors removed to see if this is responsible for harmful diversification ${ }^{32}$.

We approximate the removal of estimation errors by setting the out-of-sample expected returns each month to their actual values, and estimate the second, third and fourth moments and covariance matrix once using data for the entire sample period (1994-2015). It there are no estimation errors the Bayes diffuse prior and the Bayes-Stein shrinkage models converge to the Markowitz model. In the absence of estimation errors, but with transaction costs and non-normal returns, Table 15 shows that in terms of both CERs and Sharpe ratios, three asset portfolios perform better than two asset portfolios, and seven asset portfolios have a much better performance than two asset portfolios ${ }^{33}$. The significant positive coefficients, particularly for the seven asset portfolios, indicate that even when transaction costs and non-normality are present, diversification is highly beneficial if there are no estimation errors. This implies that harmful diversification is primarily due to estimation errors, not transaction costs or nonnormality.

\section{INSERT TABLE 15 NEAR HERE}

8.3.2 Estimation Errors and the Credit Crisis. Our conclusions may be influenced by unusual events such as the credit crisis of 2007-2009 which falls within our data set. For example, Huang and Zhong (2013) found that the benefits of diversification into alternative assets decreased during the credit crisis, Chan

\footnotetext{
${ }^{32}$ The 158,508 portfolio problems underlying Tables 8 and 9 with only one regime were re-solved. There are no results for two regimes as, in the absence of estimation errors, returns are the same in both regimes.

33 If the six techniques that do not use expected returns are excluded, the dummy variable coefficients in Table 15 are unchanged.
} 
et al (2011) conclude that the benefits of diversification are lower during crisis periods, and Arouri et al (2014) report a decrease in diversification benefits during contagion periods. So we repeat the analysis in Table 12 for the non-credit crisis ${ }^{34}$ period $^{35}$. We report the increases in the annualized MAE, MSE and SD percentages during the credit crisis, relative to the non-crisis in Table 16. This table shows that estimation errors increased substantially during the credit crisis. The increase in estimation errors during the credit crisis is smallest for bonds, followed by hedge funds, and then equities and commodities. Emerging markets, private equity and real estate have larger increases than bonds, hedge funds, equities and commodities. Since we have previously shown that harmful diversification is caused by estimation errors, the exclusion of the credit crisis will reduce the harmful diversification. Therefore we expect the impact of excluding the credit crisis on harmful diversification to be largest for emerging markets, private equity and real estate.

\section{INSERT TABLE 16 NEAR HERE}

To investigate this we exclude the utility values for the credit crisis months and recompute Table 8, with the results in Table 17 . These results are substantially different from those in Table 8. Diversification into real estate, private equity and emerging markets is now beneficial, although diversification into commodities remains harmful. There is also some limited evidence that diversification into hedge funds remains harmful. Diversification from equities and bonds into each of the alternative assets in a three asset portfolio is mostly beneficial when the credit crisis is excluded, although for highly risk averse investors there is still some evidence of harmful diversification. These results are consistent with those in Table 16, as the assets with the largest increase in estimation errors during the credit crisis are also those where diversification is harmful for the full sample, but beneficial outside the credit crisis period. This supports the conclusion that the harmful diversification results for real estate, private equity and emerging markets are due to the large estimation errors for these assets during the credit crisis. Diversification into commodities, and to a lesser extent hedge funds, with their smaller estimation errors during the credit crisis, remains harmful when the credit crisis is removed.

\section{INSERT TABLE 17 NEAR HERE}

We repeat the analysis in Table 17, where the credit crisis period is excluded, but using Sharpe ratios as the dependent variable, and these results are available from the authors. Diversification into commodities remains harmful, and there is some weak evidence that diversification into hedge funds and

\footnotetext{
${ }^{34}$ Following lyer et al (2014) and Gorton (2009), we define the period of the credit crisis as the 20 months of August 2007 to March 2009.

${ }^{35} 6$ In common with previous studies, we find the average correlation rose during the credit crisis from 0.331 to 0.546 during the crisis.
} 
all seven assets also remains harmful. For both private equities and emerging markets the evidence is mixed - sometimes diversification is harmful, and sometimes it is beneficial. Finally diversification into real estate is generally beneficial when the credit crisis is dropped. Therefore the Sharpe ratio results are mixed, and more supportive of harmful diversification than those for CERs.

The use of a two-regime model should help to deal with high volatility periods such as the credit crisis. The two-regime models in Tables $8,9,11,12,13,14$, and 15 cover the full data period and treat observations in the high and low volatility regimes differently. All the months during the credit crisis, as well as other high volatility and low return periods, are assigned by the regime switching model to the high volatility regime, and this should provide some allowance for unusual periods, such as the credit crisis. In Table 8, with one exception, all the coefficients for two regimes with a three year rolling window are larger than when only one regime is used, which suggests that the use of two regimes has, to some extent, controlled for the credit crisis. However when a four year rolling window is used, although the real estate and private equity coefficients still increase with a two-regime model, all the coefficients for commodities, hedge funds and emerging markets become smaller, i.e. diversification into these three assets becomes more harmful when a two-regime model is used. The Sharpe ratios in Table 9 exhibit the same patterns as in Table 8. When both of the two-regime cases are considered together, the evidence of harmful diversification remains present, indicating that across both three and four year estimation periods the two-regime model has not controlled for the effects of the credit crisis.

\section{Conclusions}

The main question we address is whether investing in alternative assets is beneficial for US investors. To this end we analyse the effects of adding five alternative assets (commodities, hedge funds, real estate, private equity and emerging markets) to US equity and bond portfolios over the 1997 to 2015 period. We form portfolios using 19 portfolio models, together with different lengths of rolling window, three levels of risk aversion, and with asset returns modelled assuming one or two regimes. Dummy variable regression is used to control for differences between the 19 portfolio models. Out-of-sample portfolio performance is measured by both certainty equivalent returns (CERs) and Sharpe ratios. Transaction costs are included when forming portfolios and evaluating performance. We find that adding alternative assets reduces portfolio performance, i.e. diversification is harmful. The Sharpe ratio results indicate more strongly than the CER results that diversification is harmful.

We then investigate three possible causes for this result - estimation errors, transaction costs and non-normal returns. The prime cause of harmful diversification is that alternative assets have higher estimation errors than traditional assets. Apart from hedge funds, alternative assets have higher estimation errors than equities and bonds, and the errors in predicting portfolio returns are larger for 
portfolios containing alternative assets. Estimation errors were much larger during the credit crisis (200709), particularly for alternative assets. Under such extreme market conditions, which is probably when investors most need the benefits of diversification, investment in alternative assets is harmful. It is sufficiently harmful for private equity, real estate and emerging markets that their negative performance during these 20 months outweighs their beneficial effects during the other 207 (or 185) months of the out-of-sample period. Diversification into commodities is harmful, even when there are no extreme market conditions, with some limited evidence that hedge funds also remain harmful under non-extreme market conditions. While the credit crisis is an unusual event, such events do occur in financial markets. They are hard to forecast, and difficult to distinguish from less extreme events while in progress. Our results suggest that, unless investors can predict extreme market conditions, they should avoid investing in alternative assets.

As this conclusion rules out investment in alternatives, we conducted a preliminary investigation to find a less nihilistic way forward. Our simple experiment involves varying diversification into alternatives as the predicted magnitude of their estimation errors moves above and below their long-run average. We computed the mean of the absolute estimation errors for the five alternative assets $\left(z_{t}\right)$ for each out-of-sample month. Then we set a threshold value $(T)$ for switching between the two asset and seven asset portfolios underlying Table $8^{36}$. If $z_{t-1}>T$ we invest in the two asset portfolio in the following month, and if $z_{t-1}<T$ we invest in the seven asset portfolio. We re-ran the regressions in Table 8 including CERs for the threshold switching portfolio as an eighth portfolio, giving 152 observations per regression. For seven of the twelve regressions the threshold switching portfolio has a significantly better performance at the $1 \%$ or $5 \%$ level than the equity and bond portfolio. There is no significant difference in performance for the other five regressions. So this simple illustration suggests that diversification into alternatives could be beneficial when estimation errors are predicted to be below average.

Our conclusion that diversification into alternatives is harmful depends on the way investors form portfolios, and how they estimate the inputs to their portfolio model. For example Gao and Nardari (forthcoming) use the forecast combination method of Bates and Granger (1969) to estimate out-ofsample returns, and the dynamic conditional correlation model of Engle (2002) to estimate the out-of sample covariance matrix. If investors estimate the inputs or form portfolios in a way which substantially reduces the effects of estimation errors, our conclusions may not apply. In addition, although our two performance measures (CERs and Sharpe ratios) are widely used, it is possible that a different measure

\footnotetext{
${ }^{36}$ We want a stationary threshold based on data covering a variety of market conditions, but estimation errors for alternative assets before 1997 are not available. So, for illustrative purposes, we used the average of the monthly means over our out-of-sample period (with different averages for the 3 and 4 year estimation periods), so that half the time this portfolio is the seven asset portfolio.
} 
of portfolio performance would produce different conclusions. We have examined the diversification benefits of five types of alternative asset using returns on indices of the aggregate performance of each asset type. We have not examined the diversification benefits of alternative assets when the initial portfolio is not equities and bonds. Nor have we examined the diversification benefits of the individual constituents of these five types of alternative asset, or those of other types of alternative asset.

In addition to our main result of harmful diversification, we have also found that individual asset and portfolio returns are non-normal, two regimes are present in asset returns and, except for bonds, one regime has higher volatility and lower returns than the other; the use of two regimes makes individual asset returns more normal, which supports the view that asset returns are a mixture of two normal distributions; the use of two regimes leads to much higher levels of trading; and estimation errors have a positive correlation with asset weights and are less of a problem for risk averse investors.

\section{References}

Ackermann, C., McEnally, R. and Ravenscraft, D. (1999) The Performance of Hedge Funds: Risk, Return and Incentives, Journal of Finance, vol. 54, no. 3, June, pp. 833-874.

Agarawal, V., Daniel, N.D. and Naik, N.Y. (2011) Do Hedge Funds Manage Their Reported Returns?, Review of Financial Studies, vol. 24, no. 10, October, pp. 3281-3320.

Agarawal, V., Fos, V. and Jiang, W. (2013) Inferring Reporting-Related Biases in Hedge Fund Databases from Hedge Fund Equity Holdings, Management Science, vol. 59, no. 6, June, pp. 1271-1289.

Agarawal, V., Mullally, K.A. and Naik, N.Y. (2015) The Economics and Finance of Hedge Funds: A Review of the Academic Literature, Foundations and Trends in Finance, vol. 10, no. 1, pp 1-111.

Aiken, A.L., Clifford, C.P. and Ellis, J. (2012) Out of the Dark: Hedge Fund Reporting Biases and Commercial Databases, Review of Financial Studies, vol. 26, no. 1, January, pp. 208-243.

Amin, G.S. and Kat, H.M. (2003) Hedge fund performance 1990-2000: Do the 'money machines' really add value? Journal of Financial \& Quantitative Analysis, vol. 38, no. 2, June, pp. 251-74.

Ang, A. and Bekaert, G. (2002a) Regime Switching in Interest Rates, Journal of Business and Economic Statistics, vol. 20, no. 2, April, pp. 163-182.

Ang, A., and Bekaert, G. (2002b) Short Rate Non-linearities and Regime Switches, Journal of Economic Dynamics and Control, vol. 26, nos. 7\&8, July, pp. 1243-1274.

Ang, A., and Bekaert, G. (2002c) International Asset Allocation With Regime Shifts, Review of Financial Studies, vol. 15, no. 4, Fall, pp. 1137-1187.

Ang, A., and Bekaert, G. (2004) How Regimes Affect Asset Allocation, Financial Analysts Journal, vol. 60. No. 2, March-April, pp. 86-99.

Ang, A., and Timmermann, A. (2012) Regime Changes and Financial Markets, Annual Review of Financial Economics, vol. 4, no.1, pp. 313-337.

Arouri, M.E.H., Nguyen, D.K. and Pukthuanthong, K. (2014) Diversification Benefits and Strategic Portfolio Allocation Across Asset Classes: the Case of the US Markets, Working Paper 2014-294, IPAG Business School.

Bates, J. and Granger, C. (1969) The Combination of Forecasts, Journal of the Operational Research Society, vol. 20, no. 4, December, pp. 451-468.

Bekaert, G., Erb, C.B., Harvey, C.R. and Viskanta, T.E. (1998) Distributional Characteristics of Emerging Market Returns and Asset Allocation, Journal of Portfolio Management, vol. 24, no. 2, Winter, pp. 102-116.

Bekkers, N., Doeswijk, R.Q. and Lam, T.W. (2009) Strategic Asset Allocation: Determining the Optimal Portfolio with Ten Asset Classes, Journal of Wealth Management, vol. 12, no. 3, Winter, pp. 61-77.

Belousova, J. and Dorfleitner, G. (2012) On the Diversification Benefits of Commodities from the Perspective of Euro Investors, Journal of Banking \& Finance, vol. 36, no. 9, September, pp. 2455-2472.

Bengtsson, C. (2004) The Impact of Estimation Error on Portfolio Selection for Investors with Constant Relative Risk Aversion, Working paper, Lund University.

Berger, D., Pukthuanthong, K. and Yang, J.J. (2011) International Diversification with Frontier Markets, Journal of 
Financial Economics, vol. 101, July, pp. 227-242.

Bessler, W., \& Wolff, D. (2015) Do Commodities Add Value in Multi-asset portfolios? An Out-of-sample Analysis for Different Investment Strategies, Journal of Banking \& Finance, vol. 60, November, pp. 1-20.

Bird, R., Liem, H. and Thorp, S. (2013) The Tortoise and the Hare: Risk Premium versus Alternative Asset Portfolios, Journal of Portfolio Management, vol.39, no. 3, Spring, pp. 112-122.

Boigner, P. and Gadzinski, G. (2015) Diversification With Risk Factors and Investable Hedge Fund Indices, Journal of Asset Management, vol. 16, no. 2, pp. 101-116.

Bollen, N.P.B. and Pool, V.K. (2008) Conditional Return Smoothing in the Hedge Fund Industry, Journal of Financial and Quantitative Analysis, vol. 43, no. 2, June, pp. 267-298.

Bollen, N.P.B. and Pool, V.K. (2009) Do Hedge Fund Managers Misreport Returns? Evidence from the Pooled Distribution, Journal of Finance, vol. 64, no. 5, October, pp. 2257-2288.

Bond, S.A., Hwang, S., Mitchell, P. and Satchell, S.E. (2007) Will Private Equity and Hedge Funds Replace Real Estate in Mixed-Asset Portfolios, Journal of Portfolio Management, vol. 33, Special issue, September, pp. 74-84.

Bossaerts, P. and Hillion, P. (1999) Implementing Statistical Criteria to Select Return Forecasting Models: What Do We Learn? Review of Financial Studies, vol. 12, no. 2, Summer, pp. 405-428.

Breusch, T.S. and Pagan, A.R. (1979) A Simple Test for Heteroskedasticity and Random Coefficient Variation, Econometrica, vol. 47, no. 5, September, pp. 1287-1294.

Brooks, C. and Kat, H.M. (2002) The Statistical Properties of Hedge Fund Index Returns and their Implications for Investors, Journal of Alternative Investments, vol. 5, no. 2, Fall, pp. 26-44.

Cassar, G. and Gerakos, J. (2011) Hedge Funds: Pricing Controls and the Smoothing of Self-Reported Returns, Review of Financial Studies, vol. 24, no. 5, May, pp. 1698-1734.

Cavenaile, L., Coen, A. and Hubner, G. (2011) The Impact of Illiquidity and Higher Moments of Hedge Fund Returns on Their Risk-Adjusted Performance and Diversification Potential, Journal of Alternative Investments, vol. 13, no. 4, Spring, pp. 9-29.

Chan, K.F., Treepongkaruna, S., Brooks, R. and Gray, S. (2011) Asset Market Linkages: Evidence from Financial, Commodity and Real Estate Assets, Journal of Banking and Finance, vol. 35, no. 6, June, pp. 1415-1426.

Chen, H., Ho, K., Lu, C. and Wu, C. (2005) Real estate investment trusts: an asset allocation perspective, Journal of Portfolio Management, vol. 31, special issue, September, pp. 46-55.

Cho, D.D. (2011) Estimation Risk in Covariance, Journal of Asset Management, vol. 12, no. 4, pp. 248-259.

Chopra, V.K. and Ziemba, W.T. (1993) The Effect of Errors in Means, Variances and Covariances on Optimal Portfolio Choice, Journal of Portfolio Management, vol. 19, no. 2, Winter, pp. 6-11.

Clare, A., Seaton, J., Smith, P.N. and Thomas, S. (2016) The Trend is Our Friend: Risk Parity, Momentum and Trend Following in Global Asset Allocation, Journal of Behavioural and Experimental Finance, vol. 9, March, pp. 63-80.

Cremers, J.H., Kritzman, M. and Page, S. (2004) Optimal Hedge Fund Allocations: Do Higher Moments Matter?, Revere Street Working Paper Series, Financial Economics 272-13.

Cumming, D., Hass, L. H., and Schweizer, D. (2013) Private equity benchmarks and portfolio optimization, Journal of Banking and Finance, vol. 37, no. 9, September, pp. 3515-3528.

Cumming, D., Hass, L.H. and Schweitzer, D. (2014) Strategic Asset Allocation and the Role of Alternative Investments, European Financial Management, vol. 20, no. 3, June, pp. 521-547.

Cvitanic, Polimenis and Zapatero (2008) Optimal Portfolio Allocation with Higher Moments, Annals of Finance, vol. 4, no. 1, January, pp. 1-28.

D’Agostino, R.B., Belanger, A. and D'Agostino, R.B. Jr. (1990) A Suggestion for Using Powerful and Informative Tests of Normality, The American Statistician, vol. 44, no. 4, November, pp. 316-321.

Daskalaki, C. and Skiadopoulos, G. (2011) Should Investors Include Commodities in their Portfolios After All?, Journal of Banking and Finance, vol. 35, no. 10, October, pp. 2606-2626.

DeMiguel, V., Garlappi, L. and Uppal, R. (2009) Optimal Versus Naive Diversification: How Inefficient is the $1 / \mathrm{N}$ Portfolio Strategy?, Review of Financial Studies, vol. 22, no. 5, May, pp. 1915-1953.

Diris, B., Palm, F. and Schotman, P. (2015) Long-Term Strategic Asset Allocation: An Out-of-Sample Evaluation, Management Science, vol. 61, no. 9, September, pp. 2185-2202.

Edelman, D., Fung, W. and Hsieh, D.A. (2013) Exploring Unchartered Territories of the Hedge Fund Industry: Empirical Characteristics of Mega Hedge Fund Returns, Journal of Financial Economics, vol. 109, no. 3, September, pp. 734-758.

Edwards, A.K., Harris, L.E. and Piwowar, M.S. (2007) Corporate Bond Market Transaction Costs and Transparency, Journal of Finance, vol. 62, no. 3, June, pp. 1421-1451.

Eeckoudt, L. and Schlesinger, H. (2006) Putting Risk in its Proper Place, American Economic Review, vol. 96, no. 1, 
March, pp. 280-289.

Egozcue, M., Garcia, L.F., Wong, W.K. and Zitikis, R. (2011) Do Investors Like to Diversify? A Study of Markowitz Preferences, European Journal of Operational Research, vol. 215, no. 1, November, pp. 188-193.

Engle, R. (2002) Dynamic Conditional Correlation: A Simple Class of Multivariate Generalized Autoregressive Conditional Heteroskedasticity Models, Journal of Business and Economic Statistics, vol. 20, no. 3, pp. 339350.

Ennis, R.M. and Sebastian, M.D. (2005) Asset Allocation with Private Equity, Journal of Private Equity, vol. 8, no. 3, Summer, pp. 81-87.

Evans, J.L. and Archer, S.H. (1968) Diversification and the Reduction of Dispersion: An Empirical Analysis, Journal of Finance, vol. 23, no. 5, December, pp. 761-767.

French, K.R. (2008) The Cost of Active Investing, Journal of Finance, vol. 63, no. 4, August, pp. 1537-1573.

Fung, W. and Hsieh, D.A. (2000) Performance Characteristics of Hedge Funds and Commodity Funds: Natural vs. Spurious Biases, Journal of Financial and Quantitative Analysis, vol. 35, no. 3, September, pp. 291-307.

Fung, W. and Hsieh, D.A. (2002) Hedge Fund Benchmarks: Information Content and Biases, Financial Analysts Journal, vol. 58, no. 1, March, pp. 22-34.

Fung, W. and Hsieh, D.A. (2004) Hedge Fund Benchmarks: A Risk-Based Approach, Financial Analysts Journal, vol. 60, no. 5, September-October, pp. 65-80.

Gao, X. and Nardari, F. (forthcoming) Do Commodities Add Economic Value in Asset Allocation? New Evidence from Time-Varying Moments, Journal of Financial and Quantitative Analysis.

Garlappi, L. and Skoulakis, G. (2011) Taylor Series Approximations to Expected Utility and Optimal Portfolio Choice, Mathematics and Financial Economics, vol. 5, no. 2, September, pp. 121-156.

Geltner, D.M. (1991) Smoothing in Appraisal-Based Returns, Journal of Real Estate Finance and Economics, vol. 4, no. 3, September, pp. 327-345.

Geltner, D.M. (1993) Estimating Market Values from Appraised Values Without Assuming an Efficient Market, Journal of Real Estate Research, vol. 8, no. 3, Summer, pp. 325-345.

Getmansky, M., Lo, A.W. and Makarov, I. (2004) An Econometric Model of Serial Correlation and Illiquidity in Hedge Fund Returns, Journal of Financial Economics, vol. 74, no. 3, December, pp. 529-609.

Gorton, G. (2009) Information, Liquidity and the (Ongoing) Panic of 2007, American Economic Review, vol. 99 , no. 2, May, pp. 567-572.

Gorton, G. and Rouwenhorst, K.G. (2006) Facts and Fantasies about Commodity Futures, Financial Analysts Journal, vol. 62, no. 2, March-April, pp. 47-68.

Guidolin, M. (2011) Markov Switching in Portfolio Choice and Asset Pricing Models: A Survey. In Missing Data Methods: Time-Series Methods and Applications, edited by D.M. Drukker, Emerald Group Publications, pp. 87-178.

Hocht, S., Ng, K.H., Wolf, J. and Zagst, R. (2008) Optimal Portfolio Allocation with Asian Hedge Funds and Asian REITs, International Journal of Services Sciences, vol. 1, no. 1, pp. 36-68.

Hoevenaars, R.P.M.M., Molenaar, R.D.J., Schotman, P.C. and Steenkamp, T.B.M. (2008) Strategic Asset Allocation With Liabilities: Beyond Stocks and Bonds, Journal of Economic Dynamics and Control, vol. 32, no. 9, September, pp. 2939-2970.

Huang, J.Z. and Zhong, Z. (2013) Time Variation in Diversification Benefits of Commodity, REITs and TIPS, Journal of Real Estate Finance and Economics, vol. 46, no. 1, January, pp. 152-192.

IRRC Institute (2010) Investment Horizons: Do Managers Do What They Say? IRRC Institute and Mercer.

Iyer, R., Peydro, J.L., Da-Rocha-Lopes, S. and Schoar, A. (2014) Interbank Liquidity Crunch and the Firm Credit Crunch: Evidence from the 2007-2009 Crisis, Review of Financial Studies, vol. 27. No. 1, January, pp. 347-372.

Jackwerth, J.C. and Slavutskaya, A. (2016) The Total Benefit of Alternative Assets to Pension Fund Portfolios, Journal of Financial Markets, vol. 31, November, pp. 25-42.

Jacobs, H., Muller, S. and Weber, M. (2014) How Should Individual Investors Diversify? An Empirical Evaluation of Alternative Asset Allocation Policies, Journal of Financial Markets, vol. 19, June, pp. 62-85.

Jennings, W.W. and Payne, B.C. (2016) Fees Eat Diversification's Lunch, Financial Analysts Journal, vol. 72, no. 2, March-April, pp. 31-40.

Jondeau, E. and Rockinger, M. (2006) Optimal Portfolio Allocation Under Higher Moments, European Financial Management, vol. 12, no. 1, pp. 29-55.

Kallberg, J.G. and Ziemba, W.T. (1983) Comparison of Alternative Utility Functions in Portfolio Selection Problems, Management Science, vol. 29, no. 11, November, pp. 1257-1276.

Kallberg, J.G. and Ziemba, W.T. (1984) Mis-specifications in Portfolio Selection Problems. In Risk and Capital: Lecture Notes in Economics and Mathematical Systems, edited by G. Bamberg and K. Spremann, Springer-Verlag, 
pp. 74-85.

Kan, R. and Zhou, G. (2007) Optimal Portfolio Choice with Parameter Uncertainty, Journal of Financial and Quantitative Analysis, vol. 42, no. 3, September, pp. 621-656.

Kim, C.J. (1994) Dynamic Linear Models with Markov Switching. Journal of Econometrics, vol. 60, no. 1-2, JanuaryFebruary, pp. 1-22.

Kirby, C. and Ostdiek, B. (2012) It's All in the Timing: Simple Active Portfolio Strategies that Outperform Naive Diversification, Journal of Financial and Quantitative Analysis, vol. 47. No. 2, April, pp. 437-467.

Kolm, P.N., Tutuncu, R. and Fabozzi, F.J. (2014) 60 Years of Portfolio Optimization: Practical Challenges and Current Trends, European Journal of Operational Research, vo. 234, no. 2, April, pp. 356-371.

Kourtis, A. (2015) A Stability Approach to Mean-Variance Optimization, The Financial Review, vol. 50, no. 3, August, pp. 301-330.

Ledoit, O. and Wolf, M. (2004) A Well-Conditioned Estimator for Large-Dimensional Covariance Matrices, Journal of Multivariate Analysis, vol. 88, no. 2, February, pp. 365-411.

Lee, S. and Stevenson, S. (2005) The case for REITs in the mixed-asset portfolio in the short and long run, Journal of Real Estate Portfolio Management, vol. 11, no. 1, January-April, pp. 55-80.

Levene, H. (1960) Robust Tests for Equality of Variances. In Contributions to Probability and Probability and Statistics: Essays in Honor of Harold Hotelling, edited by I. Olkin, S.G. Ghurye, W. Hoeffding, W.G. Madow and H.B. Mann, Stanford University Press, pp. 278-292.

Levy, H. and Simaan, Y. (2016) More Possessions, More Worry, European Journal of Operational Research, vol. 255, no. 3, December, pp. 893-902.

Loistl, O. (1976) The Erroneous Approximation of Expected Utility by Means of a Taylor's Series Expansion: Analytic and Computational Results, American Economic Review, vol. 66, no. 5, December, pp. 904-910.

Los, C.A. (2003) Financial Market Risk: Measurement and Analysis, Routledge.

Malkiel, B.G. and Saha, A. (2005) Hedge Funds: Risk and Return, Financial Analysts Journal, vol. 61, no. 6, NovemberDecember, pp. 80-88.

Markowitz, H. (1952) Portfolio Selection, Journal of Finance, vol. 7, no. 1, March, pp. 77-91.

Michaud, R.O. and Michaud, R.O. (2008) Efficient Asset Management: A Practical Guide to Stock Portfolio Optimization, Oxford University Press, Second edition.

Myer, F.C.N. and Webb, J.R. (1994) Statistical Properties of Returns: Financial Assets Versus Commercial Real Estate, Journal of Real Estate Finance and Economics, vol. 8, no. 3, May, pp. 267-282.

OECD (2016) Annual Survey of Large Pension Funds and Public Pension Reserve Funds 2015, OECD, 56 pages.

Oikonomou, I., Platanakis, E., and Sutcliffe, C. (forthcoming) Socially Responsible Investment Portfolios: Does the Optimization Process Matter? British Accounting Review.

Okunev, J. and White, D. (2004) An Analysis of the Risk Factors Underlying Hedge Funds Returns. In Intelligent Hedge Fund Investing, edited by B. Schachter, Risk Books, pp. 303-364.

Olivares-Nadal, A.V. and DeMiguel, V. (2015) A Robust Perspective on Transactions Costs in Portfolio Optimization, Working paper, London Business School.

Pedersen, N., Page, S. and He, F. (2014) Asset Allocation: Risk Models for Alternative Investments, Financial Analysts Journal, vol. 70, no. 3, May-June, pp. 34-45.

Perlin, M. (2015) MS_Regress - The MATLAB Package for Markov Regime Switching Models, Working paper, Federal University of Rio Grande do Sul, 39 pages.

Pictet Alternative Advisors SA (2015) Hedge Fund Indices: How Representative Are They?, Pictet, 11 pages.

Posthuma, N. and Van Der Sluis, P.J. (2003) A Reality Check on Hedge Fund Returns, Working paper, Free University of Amsterdam, 37 pages.

Sa-Aadu, J., Shilling, J. and Tiwan, A. (2010) On the Portfolio Properties of Real Estate in Good Times and Bad Times, Real Estate Economics, vol. 38, no. 3, Fall, pp. 529-565.

Scott, R.S. and Horvath, P.A. (1980) On the Direction of Preference for Moments of Higher Order Than the Variance, Journal of Finance, vol. 35, no. 4, September, pp. 915-919.

Smetters, K. and Zhang, X. (2014) A Sharper Ratio: A General Measure for Correctly Ranking Non-Normal Investment Risks, Working paper, University of Pennsylvania, 40 pages.

Stuart, A., Ord, J.K. and Arnold, S. (1999) Kendall's Advanced Theory of Statistics, vol 2A, Arnold, London.

Thornton, D.L. and Valente, G. (2012) Out-of-Sample Predictions of Bond Excess Returns and Forward Rates: An Asset Allocation Perspective, Review of Financial Studies, vol. 25, no. 10, October, pp. 3140-3168.

Timmermann, A. (2000) Moments of Markov Switching Models, Journal of Econometrics, vol. 96, no. 1, May, pp. 75111.

Towers Watson (2015) Towers Watson Global Pension Assets Study 2015, Towers Watson. 
Tu, J. (2010) Is Regime Switching in Stock Returns Important in Portfolio Decisions?, Management Science, vol. 56, no. 7, July, pp. 1198-1215.

Tu, J. and Zhou, G. (2004) Data-Generating Process Uncertainty: What Difference Does it Make in Portfolio Decisions?, Journal of Financial Economics, vol. 72, no. 2, May, pp. 385-421.

Welch, I. and Goyal, A. (2008) A Comprehensive Look at the Empirical Performance of Equity Premium Prediction, Review of Financial Studies, vol. 21, No. 4, July, pp. 1455-1508.

Willis Towers Watson (2017) Global Alternatives Survey 2017, Willis Towers Watson, July, 96 pages.

Woodside-Oriakhi, M., Lucas, C. and Beasley, J.E. (2013) Portfolio Rebalancing with an Investment Horizon and Transactions Costs, Omega, vol. 41, no. 2, April, pp. 406-420.

Xiong, J.X. and Idzorek, T.M. (2011) The Impact of Skewness and Fat Tails on the Asset Allocation Decision, Financial Analysts Journal, vol. 67, no. 2, March-April, pp. 23-35. 
Table 1: The First Four Moments and Normality Tests, Annualized Returns - 1994-2015

\begin{tabular}{|l|c|c|c|c|c|c|c|}
\hline \multirow{2}{*}{ Asset class } & \multirow{2}{*}{$\begin{array}{c}1 \\
\text { Mean \% }\end{array}$} & \multirow{2}{*}{$\begin{array}{c}2 \\
\text { Std. Dev. \% }\end{array}$} & \multirow{2}{*}{$\begin{array}{c}3 \\
\text { Skewness }\end{array}$} & $\begin{array}{c}4 \\
\text { Kurtosis }\end{array}$ & $\begin{array}{c}\text { Jarque } \\
\text {-Bera }\end{array}$ & $\begin{array}{c}\text { Shapiro } \\
\text {-Wilk }\end{array}$ & $\begin{array}{c}\text { Anderson } \\
\text {-Darling }\end{array}$ \\
\hline Equities & 9.813 & 14.881 & $-0.193^{* * *}$ & $3.096^{* * *}$ & $32.836^{* * *}$ & $4.818^{* * *}$ & $1.537^{* * *}$ \\
\hline Bonds & 5.442 & 3.613 & -0.057 & $3.082^{* *}$ & $11.479^{* *}$ & $2.205^{* *}$ & 0.629 \\
\hline Real estate & 13.116 & 20.268 & $-0.227^{* * *}$ & $3.663^{* * *}$ & $693.496^{*}$ & $20.149^{*}$ & $4.440^{* * *}$ \\
\hline Commodities & 2.623 & 22.037 & $-0.100^{* *}$ & $3.105^{* * *}$ & $21.292^{* * *}$ & $2.600^{* * *}$ & $0.964^{* * *}$ \\
\hline Private equity & 10.731 & 24.203 & $-0.102^{* *}$ & $3.445^{* * *}$ & $304.524^{*}$ & $16.375^{*}$ & $5.371^{* * *}$ \\
\hline Emerging Mkts & 7.020 & 23.195 & $-0.192^{* * *}$ & $3.161^{* * *}$ & $58.046^{* * *}$ & $5.381^{* * *}$ & $1.174^{* * *}$ \\
\hline Hedge funds $^{+}$ & 4.979 & 8.243 & $-0.179^{* * *}$ & $3.258^{* * *}$ & $117.093^{*}$ & $6.786^{* * *}$ & $1.359^{* * *}$ \\
\hline
\end{tabular}

${ }^{+}$Hedge fund returns have been de-smoothed using the Geltner $(1991,1993)$ method. The significance of departures from normality for skewness and kurtosis rely on D'Agostino et al (1990). Significance at the 10\%, 5\% and $1 \%$ levels is denoted by $* * *$ and $* * *$ respectively for the monthly returns. 
Table 2: Correlations of Monthly Returns - 1994-2015

\begin{tabular}{|l|c|c|c|c|c|c|c|}
\hline & Equities & Bonds & $\begin{array}{c}\text { Real } \\
\text { Estate }\end{array}$ & Commodities & $\begin{array}{c}\text { Private } \\
\text { Equity }\end{array}$ & $\begin{array}{c}\text { Emerging } \\
\text { Markets }\end{array}$ & $\begin{array}{c}\text { Hedge } \\
\text { Funds }^{+}\end{array}$ \\
\hline Equities & 1 & - & - & - & - & - & - \\
\hline Bonds & 0.25 & 1 & - & - & - & - & - \\
\hline Real estate & $0.57^{* * *}$ & 0.34 & 1 & - & - & - & - \\
\hline Commodities & $0.26^{* * *}$ & 0.12 & $0.17^{* * *}$ & 1 & - & - & - \\
\hline Private equity & $0.75^{* * *}$ & $0.23^{* * *}$ & $0.61^{* *}$ & $0.38^{* * *}$ & 1 & - & - \\
\hline Emerging mkts. & $0.73^{* * *}$ & 0.25 & $0.48^{* * *}$ & $0.37^{* * *}$ & $0.73^{* * *}$ & 1 & - \\
\hline Hedge Funds & $0.63^{* * *}$ & 0.31 & $0.32^{* * *}$ & $0.38^{* * *}$ & $0.62^{* * *}$ & $0.74^{* * *}$ & 1 \\
\hline
\end{tabular}

+ Hedge fund returns have been de-smoothed using the Geltner $(1991,1993)$ method.

$* * *$ Significantly different from zero at the $1 \%$ level. 
Table 3: Portfolio Models

\begin{tabular}{|l|ll|}
\hline \multirow{4}{*}{ Mean } & 1 & Markowitz \\
Variance & 2 & Markowitz with upper generalized constraints \\
& 3 & Markowitz with lower generalized constraints \\
& 5 & Bayes diffuse prior \\
& 6 & Black-Litterman (1/N) \\
& 7 & Black-Litterman (minimum variance) \\
& 8 & Michaud - resampled efficient frontier \\
\hline & 9 & Minimum variance \\
& 10 & Minimum variance with upper generalized constraints \\
& 11 & Minimum variance with lower generalized constraints \\
Ad hoc & 12 & $1 / N$ \\
& 13 & Combination - minimum variance \& $1 / N$ \\
& 14 & Combination - minimum variance, $1 / N$ \& Markowitz tangency \\
& 15 & Risk parity \\
& 16 & Reward to risk timing \\
\hline Utility & 17 & CRRA utility (1 ${ }^{\text {st }}$ four moments) \\
Function & 18 & CRRA utility (1 ${ }^{\text {st }}$ four moments) with upper generalized constraints \\
& 19 & CRRA utility (1 ${ }^{\text {st }}$ four moments) with lower generalized constraints \\
\hline
\end{tabular}

See the Appendix for details of these models. 
Table 4: The First Four Moments of the Two Regimes, Annualized Returns - 1994-2015

\begin{tabular}{|c|c|c|c|c|c|c|c|c|}
\hline & \multicolumn{4}{|c|}{ Low Volatility Regime } & \multicolumn{4}{|c|}{ High Volatility Regime } \\
\hline & Mean \% & Std.Dev. \% & Skewness & Kurtosis & Mean \% & Std.Dev. \% & Skewness & Kurtosis \\
\hline Equities & 15.929 & 10.703 & -0.063 & 3.001 & -4.252 & 21.165 & -0.080 & 2.960 \\
\hline Bonds & 4.090 & 3.496 & $-0.092^{*}$ & $3.103^{* *}$ & 8.604 & 3.754 & -0.035 & 3.049 \\
\hline Real estate & 19.733 & 14.499 & $-0.093^{*}$ & $3.056^{*}$ & -2.103 & 29.200 & $-0.129^{*}$ & $3.406^{* * *}$ \\
\hline Commodities & 3.573 & 19.126 & -0.063 & 3.041 & 0.437 & 27.726 & -0.111 & 3.077 \\
\hline Private equity & 23.228 & 14.618 & -0.056 & $3.060^{*}$ & -18.013 & 36.812 & 0.081 & $3.173^{* * *}$ \\
\hline Emerging & 16.574 & 17.057 & -0.012 & 2.993 & -14.952 & 32.539 & -0.105 & 3.023 \\
\hline Hedge funds ${ }^{+}$ & 7.109 & 5.745 & $-0.097^{*}$ & 2.991 & 0.080 & 12.117 & -0.086 & 3.076 \\
\hline
\end{tabular}

${ }^{+}$Hedge fund returns have been de-smoothed using the Geltner $(1991,1993)$ method. The significance of departures from normality for skewness and kurtosis rely on D'Agostino et al (1990). Significance at the $10 \%, 5 \%$ and $1 \%$ levels is denoted by ${ }^{*}, *$ and $* * *$ respectively for the monthly returns. The values for the first four moments have been annualized, Cumming et al (2014). 
Table 5: Normality Tests for Two Regimes for Monthly Returns - 1994-2015

\begin{tabular}{|c|c|c|c|c|c|c|}
\hline & \multicolumn{3}{|c|}{ Low Volatility Regime } & \multicolumn{3}{|c|}{ High Volatility Regime } \\
\hline & $\begin{array}{l}\text { Jarque } \\
\text {-Bera }\end{array}$ & $\begin{array}{l}\text { Shapiro } \\
\text {-Wilk }\end{array}$ & $\begin{array}{l}\text { Anderson } \\
\text {-Darling }\end{array}$ & $\begin{array}{l}\text { Jarque } \\
\text {-Bera }\end{array}$ & $\begin{array}{l}\text { Shapiro } \\
\text {-Wilk }\end{array}$ & $\begin{array}{l}\text { Anderson } \\
\text {-Darling }\end{array}$ \\
\hline Equities & 1.452 & 1.075 & 0.749 & 1.903 & 1.404 & 0.429 \\
\hline Bonds & $13.393^{* * *}$ & $2.290^{* *}$ & 0.631 & 0.940 & 0.565 & 0.240 \\
\hline Real estate & $6.071^{* * *}$ & $1.543^{*}$ & 0.574 & $70.062^{* * *}$ & $7.001^{* * *}$ & $2.323^{* * *}$ \\
\hline Commodities & 2.958 & $2.177^{* *}$ & $1.031^{* * *}$ & 3.966 & 1.453 & 0.375 \\
\hline Private equity & $4.511^{*}$ & 1.170 & 0.384 & $12.686^{* * *}$ & $2.689^{* * *}$ & $0.944^{* *}$ \\
\hline Emerging mkts. & 0.146 & 1.269 & 0.480 & 1.807 & 1.283 & 0.277 \\
\hline Hedge funds ${ }^{+}$ & 3.554 & 1.387 & 0.443 & 3.172 & 1.216 & 0.329 \\
\hline
\end{tabular}

${ }^{+}$Hedge fund returns have been de-smoothed using the Geltner $(1991,1993)$ method. Significance at the $10 \%, 5 \%$ and $1 \%$ levels is denoted by $*, * *$ and $* * *$ respectively for the monthly returns. 
Table 6: Tests for an Equality of Means and Variances in the Two Regimes - 1994 to 2015

\begin{tabular}{|l|c|c|}
\hline & Means $^{1}$ & Variances $^{2}$ \\
\hline Equities & $2.333^{* *}$ & $62.625^{* * *}$ \\
\hline Bonds & $-2.677^{* * *}$ & 0.397 \\
\hline Real estate & 1.835 & $17.238^{* * *}$ \\
\hline Commodities & 0.265 & $14.668^{* * *}$ \\
\hline Private equity & $2.800^{* * *}$ & $48.161^{* * *}$ \\
\hline Emerging mkts. $^{* *}$ & $2.368^{* *}$ & $46.865^{* * *}$ \\
\hline Hedge funds $^{+}$ & 1.415 & $44.396^{* * *}$ \\
\hline
\end{tabular}

${ }^{+}$Hedge fund returns have been de-smoothed using the Geltner $(1991,1993)$ method. ${ }^{1} \mathrm{t}$-test statistics for equal means with unequal variances. ${ }^{2}$ Levene (1960) test statistics for unequal variances. Significance at the $10 \%, 5 \%$ and $1 \%$ levels is denoted by $*, * *$ and $* * *$ respectively for the monthly returns. 
Table 7: Number of Portfolios with Non-Normal Out-of-Sample Returns when $\lambda=5$, Three and Four Year Estimation Periods, One and Two Regimes

\begin{tabular}{|c|c|c|c|c|c|c|}
\hline \multirow{3}{*}{$\begin{array}{l}\text { Significance } \\
\text { Level }\end{array}$} & \multicolumn{6}{|c|}{ Three Year Estimation Periods - 1997-2015 } \\
\hline & \multicolumn{3}{|c|}{ One Regime } & \multicolumn{3}{|c|}{ Two Regimes } \\
\hline & $\begin{array}{c}\text { Jarque } \\
\text {-Bera }\end{array}$ & $\begin{array}{l}\text { Shapiro } \\
\text {-Wilk }\end{array}$ & $\begin{array}{c}\text { Anderson } \\
\text {-Darling }\end{array}$ & $\begin{array}{l}\text { Jarque } \\
\text {-Bera }\end{array}$ & $\begin{array}{l}\text { Shapiro } \\
\text {-Wilk }\end{array}$ & $\begin{array}{c}\text { Anderson } \\
\text {-Darling }\end{array}$ \\
\hline Insignificant & 0 & 0 & 0 & 0 & 0 & 0 \\
\hline $10 \%$ & 0 & 0 & 4 & 0 & 0 & 2 \\
\hline $5 \%$ & 0 & 0 & 10 & 2 & 0 & 11 \\
\hline \multirow[t]{2}{*}{$1 \%$} & 133 & 133 & 119 & 131 & 133 & 120 \\
\hline & \multicolumn{6}{|c|}{ Four Year Estimation Periods - 1998-2015 } \\
\hline \multirow{2}{*}{$\begin{array}{l}\text { Significance } \\
\text { Level }\end{array}$} & \multicolumn{3}{|c|}{ One Regime } & \multicolumn{3}{|c|}{ Two Regimes } \\
\hline & $\begin{array}{c}\text { Jarque } \\
\text {-Bera }\end{array}$ & $\begin{array}{l}\text { Shapiro } \\
\text {-Wilk }\end{array}$ & $\begin{array}{c}\text { Anderson } \\
\text {-Darling }\end{array}$ & $\begin{array}{l}\text { Jarque } \\
\text {-Bera }\end{array}$ & $\begin{array}{l}\text { Shapiro } \\
\text {-Wilk }\end{array}$ & $\begin{array}{c}\text { Anderson } \\
\text {-Darling }\end{array}$ \\
\hline Insignificant & 0 & 0 & 0 & 0 & 0 & 6 \\
\hline $10 \%$ & 0 & 0 & 0 & 0 & 0 & 2 \\
\hline $5 \%$ & 0 & 0 & 8 & 4 & 0 & 12 \\
\hline $1 \%$ & 133 & 133 & 125 & 129 & 133 & 113 \\
\hline
\end{tabular}


Table 8: Regression Co-efficients for Annualized CERs in Percent Using CRRA Utility Relative to EquitiesBonds and Markowitz - Three and Four Year Estimation Periods, and One and Two Regimes

\begin{tabular}{|c|c|c|c|c|c|c|}
\hline \multirow{3}{*}{$\begin{array}{l}\text { Regimes } \\
\text { Risk Aversion }\end{array}$} & \multicolumn{6}{|c|}{ Three Year Estimation Periods - 1997-2015 } \\
\hline & \multicolumn{3}{|c|}{ One Regime } & \multicolumn{3}{|c|}{ Two Regimes } \\
\hline & 2 & 5 & 10 & 2 & 5 & 10 \\
\hline Constant & $8.143^{* * *}$ & $6.545^{* * *}$ & $4.496^{* * *}$ & $5.768^{* * *}$ & $3.831^{* * *}$ & $1.779^{* * *}$ \\
\hline Equities and Bonds (E\&B) & \multicolumn{3}{|c|}{ Comparator } & \multicolumn{3}{|c|}{ Comparator } \\
\hline E\&B \& Commodities & $-1.099^{* * *}$ & $-1.214^{* * *}$ & $-1.350^{* * *}$ & -0.338 & -0.384 & -0.392 \\
\hline E\&B \& Hedge Funds ${ }^{+}$ & $-0.362^{*}$ & -0.275 & -0.278 & 0.210 & 0.319 & 0.433 \\
\hline E\&B \& Real Estate & 0.183 & -0.178 & $-0.711^{* * *}$ & $0.502^{* *}$ & 0.035 & $-0.917^{* *}$ \\
\hline E\&B \& Private Equity & $-0.599^{* * *}$ & $-0.944^{* * *}$ & $-1.512^{* * *}$ & $0.512^{* * *}$ & $0.510^{* *}$ & 0.354 \\
\hline E\&B \& Emerging Markets & 0.246 & 0.109 & -0.531 & $1.670^{* * *}$ & $0.731^{* * *}$ & 0.247 \\
\hline All Seven Assets & $-1.133^{* * *}$ & $-1.712^{* * *}$ & $-2.473^{* * *}$ & $-0.712^{* * *}$ & $-1.260^{* *}$ & $-2.406^{* * *}$ \\
\hline
\end{tabular}

18 model dummies, excluding Markowitz which is the comparator

\begin{tabular}{|l|c|c|c|c|c|c|}
\hline Adjusted R squared & 0.731 & 0.690 & 0.736 & 0.598 & 0.538 & 0.741 \\
\hline Breusch-Pagan & 3.220 & $8.00^{* *}$ & $72.91^{* * *}$ & $5.40^{* *}$ & 3.400 & $19.79^{* * *}$ \\
\hline
\end{tabular}

\begin{tabular}{|c|c|c|c|c|c|c|}
\hline \multirow{3}{*}{$\frac{\text { Regimes }}{\text { Risk Aversion }}$} & \multicolumn{6}{|c|}{ Four Year Estimation Periods - 1998-2015 } \\
\hline & \multicolumn{3}{|c|}{ One Regime } & \multicolumn{3}{|c|}{ Two Regimes } \\
\hline & 2 & 5 & 10 & 2 & 5 & 10 \\
\hline Constant & $5.656^{* * *}$ & $4.677^{* * *}$ & $2.972^{* * *}$ & $4.921^{* * *}$ & $3.620^{* * *}$ & $1.767^{* * *}$ \\
\hline Equities and Bonds (E\&B) & \multicolumn{3}{|c|}{ Comparator } & \multicolumn{3}{|c|}{ Comparator } \\
\hline E\&B \& Commodities & -0.291 & $-0.748^{* * *}$ & $-1.141^{* * *}$ & $-1.577^{* * *}$ & $-2.247^{* *}$ & $-2.448^{* * *}$ \\
\hline E\&B \& Hedge Funds ${ }^{+}$ & -0.299 & $-0.317^{* *}$ & -0.246 & $-1.077^{* * *}$ & - & $-0.849^{* *}$ \\
\hline E\&B \& Real Estate & 0.160 & $-0.492^{* * *}$ & $-1.040^{* * *}$ & $0.555^{* * *}$ & -0.254 & $-0.815^{* * *}$ \\
\hline E\&B \& Private Equity & $-0.455^{* *}$ & $-0.795^{* * *}$ & $-1.369^{* * *}$ & $0.534^{* * *}$ & $0.468^{* *}$ & 0.023 \\
\hline E\&B \& Emerging Markets & $0.886^{* * *}$ & 0.059 & $-0.705^{* *}$ & -0.251 & $-0.576^{* *}$ & $-1.345^{* * *}$ \\
\hline All Seven Assets & -0.063 & $0.533^{* * *}$ & -0.036 & $-0.415^{* *}$ & $-0.996^{* *}$ & $-2.161^{* * *}$ \\
\hline
\end{tabular}

18 model dummies, excluding Markowitz which is the comparator

\begin{tabular}{|l|c|c|c|c|c|c|}
\hline Adjusted R squared & 0.421 & 0.634 & 0.808 & 0.676 & 0.745 & 0.796 \\
\hline Breusch-Pagan & 2.280 & $13.93^{* * *}$ & $53.47^{* * *}$ & 0.060 & 2.020 & $15.58^{* * *}$ \\
\hline
\end{tabular}

${ }^{+}$Hedge fund returns have been de-smoothed using the Geltner $(1991,1993)$ method. The dependent variables are the CERs. Significance at the $10 \%, 5 \%$ and $1 \%$ levels is denoted by $* * *$ and $* * *$ respectively for the monthly returns. Where the Breusch-Pagan statistic is significant at the $5 \%$ level robust standard errors are shown in the table. 
Table 9: Regression Co-efficients for Annualized Sharpe Ratios Relative to Equities-Bonds and Markowitz Three and Four Year Estimation Periods, and One and Two Regimes

\begin{tabular}{|c|c|c|c|c|c|c|}
\hline \multirow{3}{*}{$\frac{\text { Regimes }}{\text { Risk Aversion }}$} & \multicolumn{6}{|c|}{ Three Year Estimation Periods - 1997-2015 } \\
\hline & \multicolumn{3}{|c|}{ One Regime } & \multicolumn{3}{|c|}{ Two Regimes } \\
\hline & 2 & 5 & 10 & 2 & 5 & 10 \\
\hline Constant & $0.673^{* * *}$ & $0.708^{* * *}$ & $0.745^{* * *}$ & $0.443^{* * *}$ & $0.446^{* * *}$ & $0.482^{* * *}$ \\
\hline Equities and Bonds (E\&B) & \multicolumn{3}{|c|}{ Comparator } & \multicolumn{3}{|c|}{ Comparator } \\
\hline E\&B \& Commodities & $-0.180^{* * *}$ & $-0.172^{* *}$ & $-0.168^{* * *}$ & $-0.070^{* *}$ & $-0.074^{* * *}$ & $-0.078^{* * *}$ \\
\hline E\&B \& Hedge Funds ${ }^{+}$ & $-0.048^{* *}$ & $-0.037^{*}$ & -0.040 & $0.049^{*}$ & 0.038 & 0.018 \\
\hline E\&B \& Real Estate & $-0.049^{* *}$ & $-0.049^{* *}$ & $-0.052^{* *}$ & 0.000 & 0.001 & 0.000 \\
\hline E\&B \& Private Equity & $-0.133^{* * *}$ & $-0.132^{* *}$ & $-0.127^{* * *}$ & 0.004 & 0.027 & $0.047^{*}$ \\
\hline E\&B \& Emerging Markets & $-0.081^{* * *}$ & -0.036 & -0.020 & $0.092^{* * *}$ & $0.060^{* *}$ & $0.080^{* * *}$ \\
\hline All Seven Assets & $-0.217^{* * *}$ & $-0.224^{* *}$ & $-0.220^{* * *}$ & $-0.134^{* * *}$ & $-0.135^{* * *}$ & $-0.148^{* * *}$ \\
\hline
\end{tabular}

18 model dummies excluding Markowitz which is the comparator

\begin{tabular}{|l|l|l|l|l|l|l|}
\hline Adjusted R squared & 0.848 & 0.832 & 0.843 & 0.769 & 0.782 & 0.785 \\
\hline Breusch-Pagan & 2.390 & 2.770 & 2.400 & 0.210 & 0.200 & 0.110 \\
\hline
\end{tabular}

\begin{tabular}{|c|c|c|c|c|c|c|}
\hline \multirow{3}{*}{$\frac{\text { Regime }}{\text { Risk Aversion }}$} & \multicolumn{6}{|c|}{ Four Year Estimation Periods - 1998-2015 } \\
\hline & \multicolumn{3}{|c|}{ One Regime } & \multicolumn{3}{|c|}{ Two Regimes } \\
\hline & 2 & 5 & 10 & 2 & 5 & 10 \\
\hline Constant & $0.468^{* * *}$ & $0.547^{* * *}$ & $0.589^{* * *}$ & $0.402^{* * *}$ & $0.449^{* * *}$ & $0.473^{* * *}$ \\
\hline Equities and Bonds (E\&B) & \multicolumn{3}{|c|}{ Comparator } & \multicolumn{3}{|c|}{ Comparator } \\
\hline E\&B \& Commodities & $-0.094^{* * *}$ & $-0.110^{* * *}$ & $-0.125^{* * *}$ & $-0.218^{* * *}$ & $-0.279^{* * *}$ & $-0.308^{* * *}$ \\
\hline E\&B \& Hedge Funds ${ }^{+}$ & $-0.035^{*}$ & $-0.039^{*}$ & $-0.035^{* *}$ & $-0.104^{* * *}$ & $-0.118^{* * *}$ & $-0.124^{* * *}$ \\
\hline E\&B \& Real Estate & $-0.040^{* *}$ & $-0.062^{* * *}$ & $-0.065^{* * *}$ & 0.013 & -0.038 & $-0.052^{* *}$ \\
\hline E\&B \& Private Equity & $-0.107^{* * *}$ & $-0.101^{* * *}$ & $-0.089^{* * *}$ & 0.019 & 0.027 & 0.029 \\
\hline E\&B \& Emerging Markets & 0.007 & -0.010 & -0.012 & $-0.078^{* * *}$ & $-0.075^{* * *}$ & $-0.070^{* * *}$ \\
\hline All Seven Assets & $-0.107^{* * *}$ & $-0.133^{* * *}$ & $-0.153^{* * *}$ & $-0.118^{* * *}$ & $-0.117^{* * *}$ & $-0.125^{* * *}$ \\
\hline
\end{tabular}

18 model dummies excluding Markowitz which is the comparator

\begin{tabular}{|l|l|l|l|l|l|l|}
\hline Adjusted R squared & 0.889 & 0.884 & 0.886 & 0.851 & 0.864 & 0.870 \\
\hline Breusch-Pagan & 0.050 & 0.550 & 1.340 & 0.140 & 0.030 & 0.100 \\
\hline
\end{tabular}

${ }^{+}$Hedge fund returns have been de-smoothed using the Geltner $(1991,1993)$ method. The dependent variables are the Sharpe Ratios. Significance at the $10 \%, 5 \%$ and $1 \%$ levels is denoted by *,** and $* * *$ respectively for the monthly returns. Where the Breusch-Pagan statistic is significant at the $5 \%$ level robust standard errors are shown in the table. 
Table 10: Average Reduction in Percentage Annualized Returns Due to Transaction Costs for the 19 Portfolio Models - 3 Year Estimation Period

\begin{tabular}{|c|c|c|c|c|c|c|}
\hline \multirow{3}{*}{$\frac{\text { Regimes }}{\text { Risk Aversion }}$} & \multicolumn{6}{|c|}{ Three Year Estimation Periods - 1997-2015 } \\
\hline & \multicolumn{3}{|c|}{ One Regime } & \multicolumn{3}{|c|}{ Two Regimes } \\
\hline & 2 & 5 & 10 & 2 & 5 & 10 \\
\hline Equities and Bonds (E\&B) & 0.1786 & 0.1898 & 0.1900 & 0.7874 & 0.7030 & 0.7383 \\
\hline E\&B \& Commodities & 0.2778 & 0.2793 & 0.2563 & 1.0828 & 0.9751 & 0.9636 \\
\hline E\&B \& Hedge Funds+ & 0.2584 & 0.2720 & 0.2807 & 0.9932 & 0.9206 & 0.9172 \\
\hline E\&B \& Real Estate & 0.3069 & 0.3267 & 0.3114 & 0.9047 & 0.8163 & 0.8292 \\
\hline E\&B \& Private Equity & 0.2920 & 0.2948 & 0.2779 & 1.0042 & 0.9533 & 0.9570 \\
\hline E\&B \& Emerging Markets & 0.2753 & 0.2571 & 0.2481 & 1.0386 & 0.9552 & 0.8964 \\
\hline \multirow[t]{2}{*}{ All Seven Assets } & 0.5353 & 0.5051 & 0.4638 & 1.1427 & 1.0787 & 1.1100 \\
\hline & \multicolumn{6}{|c|}{ Four Year Estimation Periods - 1998-2015 } \\
\hline Regime & \multicolumn{3}{|c|}{ One Regime } & \multicolumn{3}{|c|}{ Two Regimes } \\
\hline Risk Aversion & 2 & 5 & 10 & 2 & 5 & 10 \\
\hline Equities and Bonds (E\&B) & 0.1788 & 0.1684 & 0.1721 & 0.7936 & 0.7528 & 0.7082 \\
\hline E\&B \& Commodities & 0.2637 & 0.2400 & 0.2284 & 0.9781 & 0.9839 & 0.9089 \\
\hline E\&B \& Hedge Funds ${ }^{+}$ & 0.2587 & 0.2385 & 0.2429 & 0.9971 & 1.0031 & 0.9668 \\
\hline E\&B \& Real Estate & 0.2890 & 0.2715 & 0.2685 & 0.8788 & 0.8828 & 0.8313 \\
\hline E\&B \& Private Equity & 0.2849 & 0.2471 & 0.2318 & 1.0239 & 0.9397 & 0.8465 \\
\hline E\&B \& Emerging Markets & 0.2548 & 0.2200 & 0.2162 & 1.0209 & 0.9457 & 0.8262 \\
\hline All Seven Assets & 0.5096 & 0.4557 & 0.4152 & 1.2368 & 1.1375 & 1.0223 \\
\hline
\end{tabular}

${ }^{+}$Hedge fund returns have been de-smoothed using the Geltner $(1991,1993)$ method. 
Table 11 Annualized Percentage Changes in CERs when the Portfolio Model Allows for the Non-Normality of Asset Returns

\begin{tabular}{|c|c|c|c|c|c|c|}
\hline \multirow{3}{*}{$\frac{\text { Regimes }}{\text { Risk Aversion }}$} & \multicolumn{6}{|c|}{ Three Year Estimation Periods - 1997-2015 } \\
\hline & \multicolumn{3}{|c|}{ One Regime } & \multicolumn{3}{|c|}{ Two Regimes } \\
\hline & 2 & 5 & 10 & 2 & 5 & 10 \\
\hline CRRA relative to Markowitz & $\begin{array}{c}0.004 \\
(0.990)\end{array}$ & $\begin{array}{l}0.083 \\
(0.811)\end{array}$ & $\begin{array}{l}-0.055 \\
(0.901)\end{array}$ & $\begin{array}{l}0.003 \\
(0.995)\end{array}$ & $\begin{array}{c}0.000 \\
(1.000)\end{array}$ & $\begin{array}{l}-0.010 \\
(0.987)\end{array}$ \\
\hline $\begin{array}{l}\text { CRRA relative to Markowitz, both } \\
\text { with upper generalized constraints }\end{array}$ & $\begin{array}{l}-0.012 \\
(0.972)\end{array}$ & $\begin{array}{l}-0.001 \\
(0.998)\end{array}$ & $\begin{array}{l}-0.071 \\
(0.873)\end{array}$ & $\begin{array}{l}-0.001 \\
(0.997)\end{array}$ & $\begin{array}{l}-0.017 \\
(0.965)\end{array}$ & $\begin{array}{l}-0.036 \\
(0.952)\end{array}$ \\
\hline $\begin{array}{l}\text { CRRA relative to Markowitz, both } \\
\text { with lower generalized constraints }\end{array}$ & $\begin{array}{c}0.000 \\
(0.999)\end{array}$ & $\begin{array}{c}0.043 \\
(0.902)\end{array}$ & $\begin{array}{l}-0.065 \\
(0.884)\end{array}$ & $\begin{array}{c}0.004 \\
(0.991)\end{array}$ & $\begin{array}{l}-0.011 \\
(0.978)\end{array}$ & $\begin{array}{l}-0.029 \\
(0.962)\end{array}$ \\
\hline
\end{tabular}

\begin{tabular}{|c|c|c|c|c|c|c|}
\hline \multirow{3}{*}{$\frac{\text { Regimes }}{\text { Risk Aversion }}$} & \multicolumn{6}{|c|}{ Four Year Estimation Periods - 1998-2015 } \\
\hline & \multicolumn{3}{|c|}{ One Regime } & \multicolumn{3}{|c|}{ Two Regimes } \\
\hline & 2 & 5 & 10 & 2 & 5 & 10 \\
\hline CRRA relative to Markowitz & $\begin{array}{c}0.002 \\
(0.994)\end{array}$ & $\begin{array}{c}0.052 \\
(0.864)\end{array}$ & $\begin{array}{c}0.018 \\
(0.967)\end{array}$ & $\begin{array}{c}0.001 \\
(0.998)\end{array}$ & $\begin{array}{c}0.002 \\
(0.995)\end{array}$ & $\begin{array}{l}0.018 \\
(0.973)\end{array}$ \\
\hline $\begin{array}{l}\text { CRRA relative to Markowitz, both } \\
\text { with upper generalized constraints }\end{array}$ & $\begin{array}{c}0.015 \\
(0.962)\end{array}$ & $\begin{array}{c}0.029 \\
(0.925)\end{array}$ & $\begin{array}{l}-0.027 \\
(0.952)\end{array}$ & $\begin{array}{l}-0.005 \\
(0.986)\end{array}$ & $\begin{array}{l}-0.008 \\
(0.981)\end{array}$ & $\begin{array}{c}0.006 \\
(0.990)\end{array}$ \\
\hline $\begin{array}{l}\text { CRRA relative to Markowitz, both } \\
\text { with lower generalized constraints }\end{array}$ & $\begin{array}{c}0.007 \\
(0.983)\end{array}$ & $\begin{array}{l}0.066 \\
(0.829)\end{array}$ & $\begin{array}{l}0.026 \\
(0.954)\end{array}$ & $\begin{array}{l}-0.002 \\
(0.994)\end{array}$ & $\begin{array}{l}-0.007 \\
(0.984)\end{array}$ & $\begin{array}{c}0.000 \\
(1.000)\end{array}$ \\
\hline
\end{tabular}

Significance levels appear in brackets. The dependent variables are CERs for the three Markowitz models $(1,2$ \& 3 in Table 3). 
Table 12: Annualized Estimation Errors for Historic Estimates of Monthly Percentage Returns - Three and Four Years and One and Two Regimes

\begin{tabular}{|c|c|c|c|c|c|c|}
\hline \multirow{3}{*}{ Regimes } & \multicolumn{6}{|c|}{ Three Year Estimation Periods - 1997-2015 } \\
\hline & \multicolumn{3}{|c|}{ One Regime } & \multicolumn{3}{|c|}{ Two Regimes } \\
\hline & MAE & MSE & SD & MAE & MSE & SD \\
\hline Equities & $41.92 \%$ & $29.68 \%$ & $15.76 \%$ & $42.57 \%$ & $50.79 \%$ & $15.87 \%$ \\
\hline Bonds & $9.20 \%$ & $1.42 \%$ & $3.44 \%$ & $9.50 \%$ & $22.44 \%$ & $3.53 \%$ \\
\hline Commodities & $63.22 \%$ & $65.63 \%$ & $23.39 \%$ & $62.37 \%$ & $62.74 \%$ & $22.51 \%$ \\
\hline Hedge Funds $^{+}$ & $22.30 \%$ & $8.86 \%$ & $8.61 \%$ & $23.21 \%$ & $9.51 \%$ & $8.83 \%$ \\
\hline Real estate & $52.44 \%$ & $57.12 \%$ & $21.86 \%$ & $54.50 \%$ & $61.32 \%$ & $22.41 \%$ \\
\hline Private Equity & $63.26 \%$ & $83.53 \%$ & $26.44 \%$ & $64.54 \%$ & $84.26 \%$ & $26.23 \%$ \\
\hline \multirow[t]{2}{*}{ Emerging Markets } & $63.67 \%$ & $71.40 \%$ & $24.45 \%$ & $64.43 \%$ & $75.41 \%$ & $24.80 \%$ \\
\hline & \multicolumn{6}{|c|}{ Four Year Estimation Periods - 1998-2015 } \\
\hline \multirow[t]{2}{*}{ Regimes } & \multicolumn{3}{|c|}{ One Regime } & \multicolumn{3}{|c|}{ Two Regimes } \\
\hline & MAE & MSE & SD & MAE & MSE & SD \\
\hline Equities & $41.48 \%$ & $29.55 \%$ & $15.72 \%$ & $42.39 \%$ & $56.05 \%$ & $16.21 \%$ \\
\hline Bonds & $9.24 \%$ & $1.43 \%$ & $3.45 \%$ & $.59 \%$ & $23.26 \%$ & $3.57 \%$ \\
\hline Commodities & $63.36 \%$ & $66.25 \%$ & $23.52 \%$ & $64.22 \%$ & $70.11 \%$ & $23.85 \%$ \\
\hline Hedge Funds ${ }^{+}$ & $21.44 \%$ & $8.40 \%$ & $8.38 \%$ & $22.07 \%$ & $8.84 \%$ & $8.55 \%$ \\
\hline Real estate & $53.32 \%$ & $58.64 \%$ & $22.15 \%$ & $55.30 \%$ & $66.51 \%$ & $23.39 \%$ \\
\hline Private Equity & $64.42 \%$ & $84.86 \%$ & $26.65 \%$ & $65.99 \%$ & $94.24 \%$ & $27.82 \%$ \\
\hline Emerging Markets & $63.64 \%$ & $70.65 \%$ & $24.32 \%$ & $66.06 \%$ & 78.70\% & $25.45 \%$ \\
\hline
\end{tabular}

+ Hedge fund returns have been de-smoothed using the Geltner $(1991,1993)$ method. This table shows annualized returns. MAE is mean of the annualized absolute errors, MSE is mean of the squared annualized errors, and SD is standard deviation of the estimation errors. The figures for two regimes are averages across the portfolios in which an asset appears. 
Table 13: Percentage of the Correlations Between Estimation Errors and Asset Weights Across 14 Models that are Significantly Different from Zero at the 10\% Level, Three and Four Years and One and Two Regimes

\begin{tabular}{|c|c|c|c|c|c|}
\hline \multirow{2}{*}{$\begin{array}{l}\text { Estimation } \\
\text { Period }\end{array}$} & \multirow{2}{*}{$\lambda$} & \multicolumn{2}{|c|}{ One Regime } & \multicolumn{2}{|c|}{ Two Regimes } \\
\hline & & Positive & Negative & Positive & Negative \\
\hline \multirow{3}{*}{ Three Years } & 2 & $31.85 \%$ & 0 & $38.39 \%$ & 0 \\
\hline & 5 & 29.76 & 0 & $39.29 \%$ & 0 \\
\hline & 10 & 24.7 & 0 & $34.23 \%$ & 0 \\
\hline \multirow{3}{*}{ Four Years } & 2 & 41.37 & 0 & $45.24 \%$ & 0 \\
\hline & 5 & 36.31 & 0 & $46.13 \%$ & 0 \\
\hline & 10 & 28.57 & 0 & $44.35 \%$ & 0 \\
\hline
\end{tabular}


Table 14: Average Across 14 Models of the Annualized Mean Squared Errors for Expected Compared to Actual Portfolio Percentage Returns for $\lambda=2,5$ and 10, Three and Four Years, and One and Two Regimes

\begin{tabular}{|c|c|c|c|c|c|c|c|}
\hline \multirow{2}{*}{$\begin{array}{l}\text { Estimation } \\
\text { Period }\end{array}$} & \multirow{2}{*}{ Portfolios } & \multicolumn{3}{|c|}{ One Regime } & \multicolumn{3}{|c|}{ Two Regimes } \\
\hline & & $\lambda=2$ & $\lambda=5$ & $\lambda=10$ & $\lambda=2$ & $\lambda=5$ & $\lambda=10$ \\
\hline \multirow{7}{*}{ Three Years } & Equities and Bonds (E\&B) & $9.85 \%$ & $8.38 \%$ & $6.55 \%$ & $11.67 \%$ & $10.36 \%$ & $8.66 \%$ \\
\hline & E\&B \& Commodities & $12.66 \%$ & $10.19 \%$ & $7.63 \%$ & $12.22 \%$ & $10.35 \%$ & $8.43 \%$ \\
\hline & E\&B \& Hedge Funds ${ }^{+}$ & $9.93 \%$ & $8.40 \%$ & $6.54 \%$ & $9.90 \%$ & $8.46 \%$ & $7.06 \%$ \\
\hline & E\&B \& Real Estate & $13.27 \%$ & $11.11 \%$ & $8.66 \%$ & $15.70 \%$ & $13.73 \%$ & $11.45 \%$ \\
\hline & E\&B \& Private Equity & $14.21 \%$ & $11.99 \%$ & $9.16 \%$ & $13.42 \%$ & $10.99 \%$ & $9.35 \%$ \\
\hline & E\&B \& Emerging Markets & $15.67 \%$ & $12.71 \%$ & $9.72 \%$ & $17.57 \%$ & $14.70 \%$ & $12.18 \%$ \\
\hline & All Seven Assets & $16.07 \%$ & $13.60 \%$ & 10.25 & $17.04 \%$ & $14.93 \%$ & $12.40 \%$ \\
\hline \multirow{7}{*}{ Four Years } & Equities and Bonds (E\&B) & $9.32 \%$ & $7.75 \%$ & $5.89 \%$ & $12.00 \%$ & $10.20 \%$ & $8.70 \%$ \\
\hline & E\&B \& Commodities & $13.51 \%$ & $10.48 \%$ & $7.36 \%$ & $14.92 \%$ & $11.72 \%$ & $8.88 \%$ \\
\hline & E\&B \& Hedge Funds ${ }^{+}$ & $9.33 \%$ & $7.75 \%$ & $5.79 \%$ & $9.97 \%$ & $8.45 \%$ & $6.77 \%$ \\
\hline & E\&B \& Real Estate & $13.60 \%$ & $11.67 \%$ & $8.67 \%$ & $14.05 \%$ & $11.78 \%$ & $9.66 \%$ \\
\hline & E\&B \& Private Equity & $15.21 \%$ & $12.20 \%$ & $9.33 \%$ & $11.67 \%$ & $9.80 \%$ & $8.67 \%$ \\
\hline & E\&B \& Emerging Markets & $15.12 \%$ & $12.36 \%$ & $9.23 \%$ & $14.53 \%$ & $12.37 \%$ & $10.30 \%$ \\
\hline & All Seven Assets & $16.93 \%$ & $14.03 \%$ & 10.93 & $17.73 \%$ & $14.95 \%$ & $12.64 \%$ \\
\hline
\end{tabular}

${ }^{+}$Hedge fund returns have been de-smoothed using the Geltner $(1991,1993)$ method. 
Table 15: Regression Coefficients for Annualized CERs in Percent and Sharpe Ratios Relative to EquitiesBonds and Markowitz with No Estimation Errors - Three and Four Year Estimation Periods and One Regime

\begin{tabular}{|c|c|c|c|c|c|c|}
\hline \multirow{3}{*}{$\frac{\text { Regimes }}{\text { Risk Aversion }}$} & \multicolumn{6}{|c|}{ Three Year Estimation Periods - 1997-2015 } \\
\hline & \multicolumn{3}{|c|}{ CERs } & \multicolumn{3}{|c|}{ Sharpe Ratios } \\
\hline & 2 & 5 & 10 & 2 & 5 & 10 \\
\hline Constant & $30.193^{* * *}$ & $28.752^{* * *}$ & $26.143^{* * *}$ & $2.765^{* * *}$ & $2.752^{* * *}$ & $2.694^{* * *}$ \\
\hline Equities and Bonds & \multicolumn{3}{|c|}{ Comparator } & \multicolumn{3}{|c|}{ Comparator } \\
\hline E\&B \& Commodities & $7.154^{* * *}$ & $6.745^{* * *}$ & $5.886^{* * *}$ & $0.426^{* * *}$ & $0.420^{* * *}$ & $0.400^{* * *}$ \\
\hline E\&B \& Hedge Funds ${ }^{+}$ & 0.206 & 0.279 & 0.406 & 0.052 & 0.055 & 0.066 \\
\hline E\&B \& Real Estate & $5.628^{* * *}$ & $5.116^{* * *}$ & $4.162^{* * *}$ & $0.197^{* *}$ & $0.195^{* *}$ & $0.174^{* *}$ \\
\hline E\&B \& Private Equity & $5.756^{* * *}$ & $4.651^{* * *}$ & $3.141^{* *}$ & -0.016 & -0.029 & -0.054 \\
\hline E\&B \& Em. Mkts. & $6.157^{* * *}$ & $5.345^{* * *}$ & $4.031^{* * *}$ & $0.179^{* *}$ & $0.176^{* *}$ & $0.163^{*}$ \\
\hline All Seven Assets & $15.000^{* * *}$ & $13.828^{* * *}$ & $11.826^{* * *}$ & $0.687^{* * *}$ & $0.676^{* * *}$ & $0.642^{* * *}$ \\
\hline \multicolumn{7}{|c|}{18 model dummies excluding Markowitz which is the comparator } \\
\hline Adjusted R squared & 0.892 & 0.886 & 0.875 & 0.922 & 0.919 & 0.916 \\
\hline \multirow[t]{2}{*}{ Breusch-Pagan } & 0.700 & 0.930 & 0.730 & 1.310 & 0.990 & 0.380 \\
\hline & \multicolumn{6}{|c|}{ Four Year Estimation Periods - 1998-2015 } \\
\hline Regime & \multicolumn{3}{|c|}{ CERs } & \multicolumn{3}{|c|}{ Sharpe Ratios } \\
\hline Risk Aversion & 2 & 5 & 10 & 2 & 5 & 10 \\
\hline Constant & $29.338^{* * *}$ & $27.974^{* * *}$ & $25.483^{* * *}$ & $2.734^{* * *}$ & $2.723^{* * *}$ & $2.667^{* * *}$ \\
\hline Equities and Bonds & \multicolumn{3}{|c|}{ Comparator } & \multicolumn{3}{|c|}{ Comparator } \\
\hline E\&B \& Commodities & $7.482^{* * *}$ & $7.035^{* * *}$ & $6.113^{* * *}$ & $0.431^{* * *}$ & $0.427^{* * *}$ & $0.408^{* * *}$ \\
\hline E\&B \& Hedge Funds ${ }^{+}$ & 0.245 & $0.318^{* * *}$ & 0.441 & 0.062 & 0.065 & 0.076 \\
\hline E\&B \& Real Estate & $5.791^{* * *}$ & $5.250^{* * *}$ & $4.258^{* * *}$ & $0.198^{* *}$ & $0.196^{* *}$ & $0.175^{* *}$ \\
\hline E\&B \& Private Equity & $6.106^{* * *}$ & $4.927^{* * *}$ & $3.322^{* *}$ & -0.013 & -0.026 & -0.051 \\
\hline E\&B \& Em. Mkts. & $6.503^{* * *}$ & $5.656^{* * *}$ & $4.281^{* * *}$ & $0.191^{* *}$ & $0.189^{* *}$ & $0.175^{* *}$ \\
\hline All Seven Assets & $15.622^{* * *}$ & $14.377^{* * *}$ & $12.259^{* * *}$ & $0.701^{* * *}$ & $0.692^{* * *}$ & $0.658^{* * *}$ \\
\hline \multicolumn{7}{|c|}{18 model dummies excluding Markowitz which is the comparator } \\
\hline Adjusted R squared & 0.889 & 0.882 & 0.872 & 0.925 & 0.922 & 0.918 \\
\hline Breusch-Pagan & 0.830 & 1.080 & 0.860 & 1.080 & 0.810 & 0.250 \\
\hline
\end{tabular}

${ }^{+}$Hedge fund returns have been de-smoothed using the Geltner $(1991,1993)$ method. The dependent variables are CERs in the left hand panels and Sharpe ratios in the right hand panels. Significance at the $10 \%, 5 \%$ and $1 \%$ levels is denoted by $*, * *$ and $* * *$ respectively for the monthly returns. Where the Breusch-Pagan statistic is significant at the $5 \%$ level robust standard errors are shown in the table. 
Table 16: Differences in the Annualized Estimation Errors for Historic Estimates of Monthly Percentage Returns: Credit Crisis Period Minus the Non-Credit Crisis Period - Three and Four Years and One and Two Regimes

\begin{tabular}{|c|c|c|c|c|c|c|}
\hline \multirow{3}{*}{ Regimes } & \multicolumn{6}{|c|}{ Three Year Estimation Periods - 1997-2015 } \\
\hline & \multicolumn{3}{|c|}{ One Regime } & \multicolumn{3}{|c|}{ Two Regimes } \\
\hline & MAE & MSE & SD & MAE & MSE & SD \\
\hline Equities & $20.29 \%$ & $36.81 \%$ & $6.37 \%$ & $18.15 \%$ & $83.39 \%$ & $7.72 \%$ \\
\hline Bonds & $4.55 \%$ & $1.71 \%$ & $1.83 \%$ & $5.50 \%$ & $25.59 \%$ & $2.32 \%$ \\
\hline Commodities & $48.24 \%$ & $106.55 \%$ & $14.85 \%$ & $31.09 \%$ & $57.33 \%$ & $8.90 \%$ \\
\hline Hedge Funds ${ }^{+}$ & $17.62 \%$ & $14.96 \%$ & $5.01 \%$ & $20.92 \%$ & $16.06 \%$ & $6.16 \%$ \\
\hline Real estate & $58.64 \%$ & $183.00 \%$ & $23.09 \%$ & $59.56 \%$ & $170.98 \%$ & $23.36 \%$ \\
\hline Private Equity & $51.07 \%$ & $165.04 \%$ & $14.68 \%$ & $45.21 \%$ & $120.08 \%$ & $14.36 \%$ \\
\hline \multirow[t]{2}{*}{ Emerging Markets } & $53.07 \%$ & $118.77 \%$ & $14.03 \%$ & $47.07 \%$ & $112.36 \%$ & $15.45 \%$ \\
\hline & \multicolumn{6}{|c|}{ Four Year Estimation Periods - 1998-2015 } \\
\hline \multirow[t]{2}{*}{ Regimes } & \multicolumn{3}{|c|}{ One Regime } & \multicolumn{3}{|c|}{ Two Regimes } \\
\hline & MAE & MSE & SD & MAE & MSE & SD \\
\hline Equities & $21.15 \%$ & $38.49 \%$ & $6.53 \%$ & $19.67 \%$ & $107.80 \%$ & $8.88 \%$ \\
\hline Bonds & $4.40 \%$ & $1.71 \%$ & $1.83 \%$ & $5.52 \%$ & $31.32 \%$ & $2.31 \%$ \\
\hline Commodities & $50.06 \%$ & $111.66 \%$ & $15.09 \%$ & $44.74 \%$ & $102.18 \%$ & $14.01 \%$ \\
\hline Hedge Funds ${ }^{+}$ & $19.01 \%$ & $15.77 \%$ & $5.36 \%$ & $19.36 \%$ & $13.81 \%$ & $5.51 \%$ \\
\hline Real estate & $58.77 \%$ & $188.65 \%$ & $23.15 \%$ & $64.61 \%$ & $201.70 \%$ & $25.95 \%$ \\
\hline Private Equity & $52.96 \%$ & $175.97 \%$ & $15.12 \%$ & $51.10 \%$ & $161.34 \%$ & $18.76 \%$ \\
\hline Emerging Markets & $54.53 \%$ & $123.75 \%$ & $14.54 \%$ & $55.20 \%$ & $145.77 \%$ & $19.13 \%$ \\
\hline
\end{tabular}

${ }^{+}$Hedge fund returns have been de-smoothed using the Geltner $(1991,1993)$ method. This table shows annualized returns. MAE is mean of the annualized absolute errors, MSE is mean of the squared annualized errors, and SD is standard deviation of the estimation errors. The figures for two regimes are averages across the portfolios in which an asset appears. 
Table 17: Regression Co-efficients for Annualized CERs in Percent Relative to Equities-Bonds and Markowitz - Three and Four Year Estimation Periods, and One and Two Regimes - Credit Crisis Excluded

\begin{tabular}{|c|c|c|c|c|c|c|}
\hline \multirow{3}{*}{$\begin{array}{l}\text { Regimes } \\
\text { Risk Aversion }\end{array}$} & \multicolumn{6}{|c|}{ Three Year Estimation Periods - 1997-2015 } \\
\hline & \multicolumn{3}{|c|}{ One Regime } & \multicolumn{3}{|c|}{ Two Regimes } \\
\hline & 2 & 5 & 10 & 2 & 5 & 10 \\
\hline Constant & $9.902^{* * *}$ & $8.096^{* * *}$ & $5.480^{* * *}$ & $7.578^{* * *}$ & $5.633^{* * *}$ & $3.519^{* * *}$ \\
\hline Equities and Bonds (E\&B) & \multicolumn{3}{|c|}{ Comparator } & \multicolumn{3}{|c|}{ Comparator } \\
\hline E\&B \& Commodities & $-1.240^{* * *}$ & $-1.210^{* * *}$ & $-1.132^{* * *}$ & $-0.858^{* * *}$ & $-0.846^{* * *}$ & $-0.755^{* * *}$ \\
\hline E\&B \& Hedge Funds ${ }^{+}$ & -0.258 & -0.215 & -0.208 & -0.014 & 0.005 & -0.021 \\
\hline E\&B \& Real Estate & $0.924^{* * *}$ & $0.482^{*}$ & 0.060 & $1.934^{* * *}$ & $1.414^{* * *}$ & $0.777^{* * *}$ \\
\hline E\&B \& Private Equity & 0.327 & 0.027 & -0.393 & $1.617^{* * *}$ & $1.610^{* * *}$ & $1.566^{* * *}$ \\
\hline E\&B \& Em. Mkts. & $1.329^{* * *}$ & $1.058^{* * *}$ & $0.418^{*}$ & $2.085^{* * *}$ & $1.249^{* * *}$ & $0.745^{* * *}$ \\
\hline All Seven Assets & 0.274 & -0.303 & $-0.835^{* * *}$ & $0.680^{* * *}$ & 0.081 & $-0.529^{* *}$ \\
\hline
\end{tabular}

18 model dummies, excluding Markowitz which is the comparator

\begin{tabular}{|l|l|l|l|l|l|l|}
\hline Adjusted R squared & 0.825 & 0.653 & 0.380 & 0.764 & 0.680 & 0.613 \\
\hline Breusch-Pagan & 0.920 & 0.340 & 1.160 & 0.870 & 0.040 & 0.600 \\
\hline
\end{tabular}

\begin{tabular}{|l|l|l|}
\hline & Four Year Estimation Periods - 1998-2015
\end{tabular}

\begin{tabular}{|c|c|c|c|c|c|c|}
\hline \multirow{2}{*}{$\frac{\text { Regimes }}{\text { Risk Aversion }}$} & \multicolumn{3}{|c|}{ One Regime } & \multicolumn{3}{|c|}{ Two Regimes } \\
\hline & 2 & 5 & 10 & 2 & 5 & 10 \\
\hline Constant & $7.588^{* * *}$ & $6.367^{* * *}$ & $4.233^{* * *}$ & $6.027^{* * *}$ & $4.612^{* * *}$ & $2.503^{* * *}$ \\
\hline Equities and Bonds (E\&B) & \multicolumn{3}{|c|}{ Comparator } & \multicolumn{3}{|c|}{ Comparator } \\
\hline E\&B \& Commodities & -0.112 & $-0.556^{* * *}$ & $-0.819^{* * *}$ & $-1.003^{* * *}$ & $-1.813^{* * *}$ & $-2.011^{* * *}$ \\
\hline E\&B \& Hedge Funds ${ }^{+}$ & -0.249 & -0.247 & -0.183 & $-0.915^{* * *}$ & $-0.917^{* * *}$ & $-0.776^{* *}$ \\
\hline E\&B \& Real Estate & $0.905^{* * *}$ & $0.509^{* * *}$ & -0.026 & $1.679^{* * *}$ & $0.761^{* * *}$ & 0.256 \\
\hline E\&B \& Private Equity & $1.039^{* * *}$ & $0.611^{* * *}$ & 0.121 & $1.777^{* * *}$ & $1.826^{* * *}$ & $1.726^{* * *}$ \\
\hline E\&B \& Em. Mkts. & $2.033^{* * *}$ & $1.377^{* * *}$ & $0.677^{* * *}$ & 0.223 & -0.019 & $-0.614^{* *}$ \\
\hline All Seven Assets & $2.225^{* * *}$ & $0.588^{* * *}$ & -0.205 & $1.451^{* * *}$ & $1.023^{* * *}$ & 0.193 \\
\hline
\end{tabular}

18 model dummies, excluding Markowitz which is the comparator

\begin{tabular}{|l|l|l|l|l|l|l|}
\hline Adjusted R squared & 0.743 & 0.678 & 0.511 & 0.810 & 0.812 & 0.726 \\
\hline Breusch-Pagan & 3.120 & $9.25^{* *}$ & 1.770 & 2.000 & 1.710 & 0.000 \\
\hline
\end{tabular}

\footnotetext{
${ }^{+}$Hedge fund returns have been de-smoothed using the Geltner $(1991,1993)$ method. The dependent variables are the CERs. Significance at the $10 \%, 5 \%$ and $1 \%$ levels is denoted by $*, * *$ and $* * *$ respectively for the monthly returns. The excluded months are August 2007 to March 2009. Where the Breusch-Pagan statistic is significant at the $5 \%$ level robust standard errors are shown in the table.
} 


\section{APPENDIX - Portfolio Models}

Where applicable, all the portfolio models we use are subject to no short selling constraints, normalization of portfolio weights (weights sum to 1), and upper bounds on asset weights.

Mean-variance (Markowitz). In the Markowitz (1952) mean-variance portfolio model, investors trade-off between the mean and variance of portfolio returns. Portfolio weights are computed by maximizing a quadratic utility function using the sample mean $(\boldsymbol{\mu})$ and covariance matrix $(\boldsymbol{\Sigma})$ of asset returns.

Bayes-Stein shrinkage. The Bayes-Stein model (Jorion, 1986) is designed to tackle estimation errors in mean returns and the covariance matrix of asset returns. The Bayes-Stein model computes the column vector of mean returns $\left(\boldsymbol{\mu}_{\mathrm{BS}}\right)$ as follows:-

$$
\boldsymbol{\mu}_{\mathrm{BS}}=(1-\mathrm{g}) \boldsymbol{\mu}+\mathrm{g} \mu_{G M V} \mathbf{1}
$$

where $g=\frac{\mathrm{N}+2}{(\mathrm{~N}+2)+T\left(\boldsymbol{\mu}-\mu_{G M V} \mathbf{1}\right)^{\mathrm{T}} \Sigma^{-1}\left(\boldsymbol{\mu}-\mu_{G M V} \mathbf{1}\right)}$ is the shrinkage factor $(0 \leq g \leq 1), \mu_{G M V}$ denotes the expected return of the minimum variance portfolio when short selling is permitted, $\mathbf{1}$ is a column vector of ones and $T$ is the sample size (estimation period's length).The Bayes-Stein estimator of the covariance matrix of the asset returns $\left(\boldsymbol{\Sigma}_{\mathrm{BS}}\right)$ is given by:-

$$
\boldsymbol{\Sigma}_{\mathrm{BS}}=\left(\frac{T+\varphi+1}{T+\varphi}\right) \boldsymbol{\Sigma}+\frac{\varphi}{T(T+\varphi+1)} \frac{\mathbf{1 1}^{\mathrm{T}}}{\mathbf{1}^{\mathrm{T}} \boldsymbol{\Sigma}^{-1} \mathbf{1}}
$$

where the scalar $\varphi=\frac{\mathrm{N}+2}{\left(\boldsymbol{\mu}-\mu_{G M V} \mathbf{1}\right)^{\mathrm{T}} \Sigma^{-1}\left(\boldsymbol{\mu}-\mu_{G M V} \mathbf{1}\right)}$ represents the precision of the prior distribution of returns. We use the Bayes-Stein estimates $\left(\boldsymbol{\mu}_{\mathrm{BS}}, \boldsymbol{\Sigma}_{\mathrm{BS}}\right)$.

Bayes diffuse prior. With a diffuse prior $\left(p(\mu, \Sigma) \propto|\Sigma|^{-\frac{1}{2}(\mathrm{~N}+1)}\right)$ and a normal conditional likelihood, Barry (1974) amongst others, has shown that the predictive distribution of asset returns follows a student's $t$-distribution with mean $\boldsymbol{\mu}$ and variance $(1+1 / T) \boldsymbol{\Sigma}$. This portfolio model increases the 
covariance matrix by $(1+1 / T)$, while the historical estimate of mean returns remains unchanged. We use the Bayesian diffuse-prior estimates $(\boldsymbol{\mu},(1+1 / T) \boldsymbol{\Sigma})$.

Black-Litterman. This model combines the investor's subjective views of expected returns and risks with a benchmark (reference) portfolio. Black and Litterman (1992) compute the posterior column vector of mean returns $\left(\boldsymbol{\mu}_{\mathrm{BL}}\right)$ as follows:-

$$
\boldsymbol{\mu}_{\mathrm{BL}}=\left[(c \boldsymbol{\Sigma})^{-1}+\boldsymbol{P}^{\mathrm{T}} \boldsymbol{\Omega}^{-1} \boldsymbol{P}\right]^{-1}\left[(c \boldsymbol{\Sigma})^{-1} \mathbf{H}+\boldsymbol{P}^{\mathrm{T}} \boldsymbol{\Omega}^{-1} \mathbf{Q}\right]
$$

where $\boldsymbol{P}$ is the identity matrix defining the assets involved in each view, $\mathbf{Q}$ is a column vector of the investor's views on asset returns, and $c$ denotes the overall level of confidence in the implied asset returns. The column vector of implied returns for the reference portfolio is computed as $\mathbf{H}=\lambda \Sigma \mathbf{x}^{\text {Reference }}$ where $\lambda$ is the risk aversion parameter and $\left(\mathbf{x}^{\text {Reference }}\right)$ denotes the weights of the benchmark (reference) portfolio. For the benchmark portfolio we use the $1 / N$ portfolio in one model, and the minimum variance portfolio in another model. Following Meucci (2010), the diagonal matrix $\Omega$ that contains the reliability of each view is defined as $\boldsymbol{\Omega}=\frac{1}{\delta} \boldsymbol{P} \boldsymbol{\Sigma} \boldsymbol{P}^{\mathbf{T}}$, where $\delta$ represents the overall level of confidence in the investor's views. We follow Platanakis and Sutcliffe (2017) and set $c=0.1625$ and $\delta=1$. For each estimation period we use the sample mean return of each asset as the investor's view,as in Bessler, Opfer and Wolff (2017) and Platanakis and Sutcliffe (2017). Finally, following Satchell and Scowcroft (2000), we estimate the posterior covariance matrix $\left(\boldsymbol{\Sigma}_{\mathrm{BL}}\right)$ as follows:-

$$
\boldsymbol{\Sigma}_{\mathrm{BL}}=\boldsymbol{\Sigma}+\left[(c \boldsymbol{\Sigma})^{-1}+\boldsymbol{P}^{\mathrm{T}} \boldsymbol{\Omega}^{-1} \boldsymbol{P}\right]^{-1}
$$

We use the Black-Litterman estimates $\left(\boldsymbol{\mu}_{\mathrm{BL}}, \boldsymbol{\Sigma}_{\mathrm{BL}}\right)$.

Minimum variance. For this model we minimize the portfolio variance, subject to the constraints applied to all the optimization models.

Resampled efficient (Michaud). The "re-sampled efficiency" model (Michaud and Michaud, 2008) is based on resampling asset returns to reflect the estimation errors. In each estimation period we estimate the sample means and covariances of asset returns. Then assuming asset returns are drawn 
from a multivariate normal distribution with these parameters, we draw 20 samples of asset returns, each of which is used to compute an optimal portfolio by maximizing a quadratic utility function. The average of these optimal portfolios gives the overall optimum solution for that estimation period.

$1 / \mathrm{N}$ with re-balancing. The naive diversification $(1 / N)$ model assigns a portfolio weight of $1 / N$ to each risky asset each month (e.g. $1 / \mathrm{N}$ with re-balancing, rather than $1 / \mathrm{N}$-buy-and-hold).

Risk-parity. This model requires each asset to contribute the same risk to the portfolio variance, see for instance Maillard et al. (2010).By ignoring correlations between assets the asset weights are antiproportional to their sample variance, and are estimated as follows:-

$$
\mathrm{x}_{\mathrm{i}}=\frac{1 / \sigma_{\mathrm{i}}^{2}}{\sum_{\mathrm{i}=1}^{\mathrm{N}}\left(1 / \sigma_{\mathrm{i}}^{2}\right)}, \quad \forall \mathrm{i}=1, \ldots, \mathrm{N}
$$

Reward-to-risk timing. This model, proposed by Kirby and Ostdiek (2012), is based on the reward-torisk ratio, which is defined as the mean return divided by the sample variance of each asset. This strategy over-weights assets with a higher reward-to-risk ratio (e.g. assets with higher return and lower variance).Portfolio weights are computed as follows:-

$$
\mathrm{x}_{\mathrm{i}}=\frac{\mu_{\mathrm{i}}^{+} / \sigma_{\mathrm{i}}^{2}}{\sum_{\mathrm{i}=1}^{\mathrm{N}}\left(\mu_{\mathrm{i}}^{+} / \sigma_{\mathrm{i}}^{2}\right)}, \quad \forall \mathrm{i}=1, \ldots, \mathrm{N}
$$

where $\mu_{\mathrm{i}}^{+}=\max \left(\mu_{\mathrm{i}}, 0\right)$ to rule out short selling. In the very rare cases when all asset returns are negative, an equally-weighted portfolio $(1 / N)$ is used.

CRRA utility. The CRRA (Constant Relative Risk Aversion) utility function is defined as follows:-

$$
U(W)=\frac{1}{1-\lambda} W^{1-\lambda}, \text { if } \lambda>0, \lambda \neq 1,
$$

where $\lambda$ denotes the investor's relative risk aversion parameter. Following many previous researchers, we use a Taylor series expansion up to the fourth moment to approximate the expected CRRA utility. The Taylor series expansion for the expected CRRA utility function is given by:-

$$
E(U(W)) \approx \frac{1}{1-\lambda} \bar{W}^{1-\lambda}-\frac{\lambda}{2} \bar{W}^{-(\lambda+1)} \sigma_{\mathrm{p}}^{2}+\frac{\lambda(\lambda+1)}{3 !} \bar{W}^{-(\lambda+2)} \mathrm{s}_{\mathrm{p}}^{3}-\frac{\lambda(\lambda+1)(\lambda+2)}{4 !} \bar{W}^{-(\lambda+3)} \mathrm{k}_{\mathrm{p}}^{4}
$$


where $\bar{W}=1+\mu_{\mathrm{p}}$, and $\mu_{\mathrm{p}}, \sigma_{\mathrm{p}}^{2}, \mathrm{~s}_{\mathrm{p}}^{3}, \mathrm{k}_{\mathrm{p}}^{4}$ represent respectively the expected return, variance, skewness and kurtosis of the overall portfolio return using sample-based estimates for a given vector of portfolio weights.

Generalized portfolio constraints. Inspired by DeMiguel et al. (2009), the two different versions (lower and upper) of the generalized constraints are:-

$$
\begin{gathered}
\mathbf{x} \geq a_{\text {lower }} \mathbf{1}, \text { with } a_{\text {lower }} \in[0,1 / N] \text { and } \\
\mathbf{x} \leq a_{\text {upper }} \mathbf{1} \text {, with } a_{\text {upper }} \in[1 / N, 1] .
\end{gathered}
$$

As in DeMiguel et al. (2009) for the upper and lower bounds we use the middle of their permissible range, and so $a_{\text {lower }}=(0+1 / N) / 2$ and $a_{\text {upper }}=(1 / N+1) / 2$.

Combinations of models. We consider portfolios that are combinations of the $1 / \mathrm{N}$, minimumvariance and Markowitz tangency portfolios. We apply shrinkage directly to the portfolio weights, and consider optimal linear combinations of asset weights that maximize the expected value of the utility function, as in Kan and Zhou (2007). We employ two different combination strategies; the first combines the $1 / \mathrm{N}$ and minimum-variance portfolios, and the second combines the $1 / \mathrm{N}$, minimumvariance and Markowitz tangency portfolios. These two strategies can be represented as follows:-

$$
\begin{gathered}
\mathbf{x}^{1 / \mathrm{N}-\mathrm{MV}}=\alpha_{1} \mathbf{x}^{1 / \mathrm{N}}+\alpha_{2} \mathbf{x}^{\mathrm{MV}}, \quad \alpha_{1}, \alpha_{2} \geq 0 \\
\mathbf{x}^{1 / \mathrm{N}-\mathrm{MV}-\mathrm{TP}}=\beta_{1} \mathbf{x}^{1 / \mathrm{N}}+\beta_{2} \mathbf{x}^{\mathrm{MV}}+\beta_{3} \mathbf{x}^{\mathrm{TP}}, \quad \beta_{1}, \beta_{2}, \beta_{3} \geq 0 .
\end{gathered}
$$

When computing $\mathbf{x}^{1 / \mathrm{N}}, \mathbf{x}^{\mathrm{MV}}$ and $\mathbf{x}^{\mathrm{TP}}$, the no short selling constraint and the normalization of asset weights, but not the upper bound on the sum of alternative asset weights, are applied. The coefficients $\alpha_{1}, \alpha_{2}$ for $\mathbf{x}^{1 / \mathrm{N}-\mathrm{MV}}$, and $\beta_{1}, \beta_{2}, \beta_{3}$ for $\mathbf{x}^{1 / \mathrm{N}-\mathrm{MV}-\mathrm{TP}}$ are chosen to maximize expected mean-variance (quadratic) utility, subject to the constraints we apply to our optimization problems, for both $\mathbf{x}^{1 / \mathrm{N}-\mathrm{MV}}$ and $\mathbf{x}^{1 / \mathrm{N}-\mathrm{MV}-\mathrm{TP}}$.

\section{Additional References}

Barry, C. B. (1974) Portfolio Analysis under Uncertain Means, Variances, and Covariances, Journal of Finance, vol. 29, no. 2, pp. 515-522. 
Bessler, W., Opfer H., Wolff, D., (2017) Multi-Asset Portfolio Optimization and Out-of-Sample Performance: An Evaluation of Black-Litterman, Mean Variance and Naïve Diversification Approaches. The European Journal of Finance, vol. 23, no. 1, pp. 1-30.

Black F. and Litterman R. (1992) Global Portfolio Optimization, Financial Analysts Journal, vol. 48, no. 5, September-October, pp. 28-43.

Jorion, P. (1986) Bayes-Stein Estimation for Portfolio Analysis, Journal of Financial and Quantitative Analysis, vol. 21, no. 3, September, pp. 279-292.

Maillard, S., Roncalli, T. and Teiletche, J. (2010) The Properties of Equally Weighted Risk Contribution Portfolios, Journal of Portfolio Management, vol. 36, no. 4, pp. 60-70.

Meucci, A. 2010. The Black-Litterman Approach: Original Model and Extensions, The Encyclopedia of Quantitative Finance, Wiley.

Platanakis, E and Sutcliffe, C. (2017) Asset-Liability Modelling and Pension Schemes: The Application of Robust Optimization to USS, European Journal of Finance, vol. 23, no. 4, pp. 324-352.

Satchell, S. and Scowcroft, A. (2000) A Demystification of the Black-Litterman Model: Managing Quantitative and Traditional Portfolio Construction, Journal of Asset Management, vol. 1, no. 2, September, pp. 138-150. 